\title{
Comparison of aerosol optical depths from the Ozone Monitoring Instrument (OMI) on Aura with results from airborne sunphotometry, other space and ground measurements during MILAGRO/INTEX-B
}

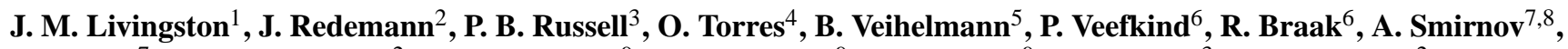 \\ L. Remer ${ }^{7}$, R. W. Bergstrom ${ }^{2}$, O. Coddington ${ }^{9}$, K. S. Schmidt ${ }^{9}$, P. Pilewskie ${ }^{9}$, R. Johnson ${ }^{3}$, and Q. Zhang ${ }^{2}$ \\ ${ }^{1}$ SRI International, Menlo Park, CA, 94025, USA \\ ${ }^{2}$ Bay Area Environmental Research Institute (BAERI), Sonoma, CA, 95476, USA \\ ${ }^{3}$ NASA Ames Research Center, Moffett Field, CA, 94035, USA \\ ${ }^{4}$ Center for Atmospheric Sciences, Hampton University, Hampton, VA, 23668, USA \\ ${ }^{5}$ European Space Agency (ESA/ESTEC), Noordwijk, The Netherlands \\ ${ }^{6}$ Royal Netherlands Meteorological Institute (KNMI), De Bilt, The Netherlands \\ ${ }^{7}$ NASA Goddard Space Flight Center, Greenbelt, MD, 20771, USA \\ ${ }^{8}$ Science Systems and Applications, Inc., Lanham, MD, 20706, USA \\ ${ }^{9}$ Laboratory for Atmospheric and Space Physics, University of Colorado, Boulder, CO, 80309, USA
}

Received: 17 March 2009 - Published in Atmos. Chem. Phys. Discuss.: 20 April 2009

Revised: 26 August 2009 - Accepted: 2 September 2009 - Published: 18 September 2009

\begin{abstract}
Airborne sunphotometer measurements are used to evaluate retrievals of extinction aerosol optical depth (AOD) from spatially coincident and temporally nearcoincident measurements by the Ozone Monitoring Instrument (OMI) aboard the Aura satellite during the March 2006 Megacity Initiative-Local And Global Research Observations/Phase B of the Intercontinental Chemical Transport Experiment (MILAGRO/INTEX-B). The 14-channel NASA Ames Airborne Tracking Sunphotometer (AATS) flew on nine missions over the Gulf of Mexico and four in or near the Mexico City area. Retrievals of AOD from near-coincident AATS and OMI measurements are compared for three flights over the Gulf of Mexico for flight segments when the aircraft flew at altitudes $60-70 \mathrm{~m}$ above sea level, and for one flight over the Mexico City area where the aircraft was restricted to altitudes $\sim 320-800 \mathrm{~m}$ above ground level over the rural area and $\sim 550-750 \mathrm{~m}$ over the city. OMImeasured top of atmosphere (TOA) reflectances are routinely inverted to yield aerosol products such as AOD and
\end{abstract}

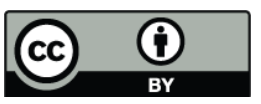

Correspondence to: J. M. Livingston (john.livingston@sri.com) aerosol absorption optical depth (AAOD) using two different retrieval algorithms: a near-UV (OMAERUV) and a multiwavelength (OMAERO) technique. This study uses the archived Collection 3 data products from both algorithms. In particular, AATS and OMI AOD comparisons are presented for AATS data acquired in 20 OMAERUV retrieval pixels (15 over water) and 19 OMAERO pixels (also 15 over water). At least four pixels for one of the over-water coincidences and all pixels for the over-land case were cloud-free. Coincident AOD retrievals from 17 pixels of the Moderate Resolution Imaging Spectroradiometer (MODIS) aboard Aqua are available for two of the overwater flights and are shown to agree with AATS AODs to within root mean square (RMS) differences of $0.00-0.06$, depending on wavelength. Near-coincident ground-based AOD measurements from ground-based sun/sky radiometers operated as part of the Aerosol Robotic Network (AERONET) at three sites in and near Mexico City are also shown and are generally consistent with the AATS AODs (which exclude any AOD below the aircraft) both in magnitude and spectral dependence. The OMAERUV algorithm retrieves AODs corresponding to a non-absorbing aerosol model for

Published by Copernicus Publications on behalf of the European Geosciences Union. 
all three over-water comparisons, whereas the OMAERO algorithm retrieves best-fit AODs corresponding to an absorbing biomass-burning aerosol model for two of the three overwater cases. For the four cloud-free pixels in one overwater coincidence (10 March), the OMAERUV retrievals underestimate the AATS AODs by $\sim 0.20$, which exceeds the expected retrieval uncertainty, but retrieved AODs agree with AATS values within uncertainties for the other two over-water events. When OMAERO retrieves AODs corresponding to a biomass-burning aerosol over water, the values significantly overestimate the AATS AODs (by up to 0.55). For the Mexico City coincidence, comparisons are presented for a non-urban region $\sim 50-70 \mathrm{~km}$ northeast of the city and for a site near the center of the city. OMAERUV retrievals are consistent with AERONET AOD magnitudes for the non-urban site, but are nearly double the AATS and AERONET AODs (with differences of up to 0.29) in the center of the city. Corresponding OMAERO retrievals exceed the AATS and/or AERONET AODs by factors of 3 to 10 .

\section{Introduction}

In March 2006 the 14-channel Ames Airborne Tracking Sunphotometer (AATS-14 or AATS) was operated on a Jetstream 31 (J31) aircraft based in Veracruz, Mexico during MILAGRO/INTEX-B (Megacity Initiative-Local and Global Research Observations/Phase B of the Intercontinental Chemical Transport Experiment; Molina et al., 2009). AATS measured aerosol optical depth (AOD) at 13 wavelengths (354-2139 nm) and columnar water vapor (CWV) in 13 flights that sampled clean and polluted airmasses over the Gulf of Mexico and Mexico City. Vertical differentiation of AOD and CWV data obtained during J31 vertical profiles yields vertical profiles of multiwavelength aerosol extinction and water vapor concentration, respectively. J31 flights were coordinated with overpasses by several satellites, including Aqua and Aura, plus flights by other aircraft, including the NASA DC-8 and King Air and the NCAR C-130.

Top of Atmosphere (TOA) reflectances measured by the Ozone Monitoring Instrument (OMI) aboard Aura are routinely inverted using two different inversion schemes, a near-UV algorithm and a multiwavelength algorithm, to yield retrievals of AOD and aerosol absorption optical depth (AAOD). During MILAGRO, there were four Aura overpasses for which OMI aerosol retrievals have been performed and AATS AOD spectra have been calculated at coincident or near-coincident times and locations. Three of these $(3,10$, and 17 March) were over water (the Gulf of Mexico), and one (19 March) was over land (in and near Mexico City). Coincident AOD retrievals from the Moderate Resolution Imaging Spectroradiometer (MODIS) aboard the Aqua satellite are available for 17 pixels for the 10 March and 17 March events, but there is only one MODIS pixel with an acceptable
(MODIS quality assurance flag 3) retrieval along the J31 track for the 19 March case study. For the 19 March case a limited number of AOD retrievals is available from groundbased sun/sky radiometers that were operated as part of the Aerosol Robotic Network (AERONET) (Holben et al., 1998) at three sites in and northeast of Mexico City: T0, T1 and T2 (Molina et al., 2009). The purpose of this paper is to evaluate the performance of the OMI AOD Collection 3 retrievals for these events by comparison with collocated AATS AODs and with MODIS and AERONET AOD retrievals, where available. In a companion paper, Redemann et al. (2009) use the AATS MILAGRO data set to present a detailed comparison of MODIS Collection 004 and Collection 005 aerosol retrievals.

Due to the relatively recent nature of the OMI aerosol data set (Aura was launched on 15 July 2004), only a few OMI aerosol validation studies have been published to date. Ahn et al. (2008) compare Collection 2 OMAERUV retrievals of AOD with corresponding retrievals from Aqua-MODIS and Terra-Multiangle Imaging Spectroradiometer (MISR) for selected collocated granules during 2006 and early 2007. In addition, they compare the seasonal variability of monthly AOD in 2006 from OMI $500 \mathrm{~nm}$, MODIS $550 \mathrm{~nm}$, and MISR $558 \mathrm{~nm}$ retrievals. Curier et al. (2008) evaluate the performance of the OMI multiwavelength retrieval algorithm for the period May-July 2005 by comparing AERONET and OMAERO AOD retrievals for measurements collected at/near a small number of AERONET sites in Western Europe, and OMAERO and MODIS AOD retrievals for 161528 collocated MODIS pixels over land and sea in the same region. In their paper presenting $\mathrm{NO}_{2}$, aerosol, and ozone data from the 2005 and 2006 Dutch Aerosol and Nitrogen Dioxide Experiments for Validation of OMI and SCHIAMACHY (DANDELIONS) project, Brinksma et al. (2008) include a time series comparison of OMAERO AOD at $440 \mathrm{~nm}$ with coincident AOD retrievals from three ground-based sun photometers (two automated and one hand-held) at Cabauw, Netherlands for five days in September 2006.

Whereas the other validation efforts to date have used ground-based sunphotometer measurements to investigate OMI AOD retrievals over land and near the sea, the current study is the first to attempt validation of OMI over-water AOD retrievals with over-water measurements from other than a satellite-borne sensor.

\section{Instruments/aerosol retrieval algorithms}

\subsection{OMI}

OMI is a nadir-viewing imaging spectrometer that measures the TOA upwelling radiances in the ultraviolet and visible $(270-500 \mathrm{~nm})$ regions of the solar spectrum with a spatial resolution of approximately $0.5 \mathrm{~nm}$ (Levelt et al., 2006). OMI flies aboard the EOS-Aura spacecraft and has 
a $2600 \mathrm{~km}$ wide swath at a spatial resolution varying nonlinearly from $13 \times 24 \mathrm{~km}^{2}$ at nadir to $28 \times 150 \mathrm{~km}^{2}$ at the swath extremes (median pixel size $15 \times 32 \mathrm{~km}^{2}$ ). Although the instrument was designed primarily for retrieval of trace gases like $\mathrm{O}_{3}, \mathrm{NO}_{2}, \mathrm{SO}_{2}$, etc., it contains valuable information on aerosols. The wavelength range around $400 \mathrm{~nm}$ can be used to detect elevated layers of absorbing aerosols such as biomass burning and desert dust plumes. EOSAura is part of the A-Train satellite constellation; thus, OMI makes near simultaneous measurements with Aqua-MODIS, PARASOL, and CALIPSO.

The reflectance at the top of the atmosphere in the wavelength range from 330 to $500 \mathrm{~nm}$ is sensitive to the aerosol concentration, size distribution, composition and vertical distribution. The micro-physical properties determine the aerosol optical properties, which are described by the aerosol extinction efficiency, single scattering albedo and phase function as a function of altitude. Although the reflectance is sensitive to the concentration, size distribution, composition and vertical distribution, it is not possible to derive all these parameters from the OMI measured reflectances because the inversion is ill-posed. The OMI measurements in the wavelength range $330-500 \mathrm{~nm}$ contain 2 to 4 degrees of freedom (independent pieces of information) on aerosol properties (Veihelmann et al., 2007). The first degree of freedom is dominated by the aerosol column content or AOD, and the size distribution, composition and altitude are mixed in the remaining independent pieces of information. Since the number of unknowns in the inversion problem is much larger, the retrievals have to be based partly on a-priori information. The a-priori information used in the OMI aerosol retrievals consists of surface reflectance and a database of aerosol models and their possible occurrence for a certain location and time of the year.

There are two algorithms for retrieving aerosol information from OMI measurements of TOA reflectance: the OMAERUV, or near-UV, algorithm; and the OMAERO, or multiwavelength, technique. The OMAERUV algorithm has a strong heritage in the TOMS aerosol retrieval algorithm (Torres et al., 2002) and uses only a small range of wavelengths in the near UV from the OMI spectrum. The OMAERO algorithm is a new approach designed for OMI and can use the wavelength range from 330 to $500 \mathrm{~nm}$. The two algorithms are described in more detail below.

The OMAERUV aerosol algorithm uses the radiances measured at 354 and $388 \mathrm{~nm}$ to retrieve UV Aerosol Index, and AOD and AAOD at $388 \mathrm{~nm}$. The algorithm is described in detail in Torres et al. (2007) and references therein (e.g. Herman et al., 1997; Torres et al., 1998, 2002). It uses the same technique as that used in TOMS aerosol retrievals (Torres et al., 1998). There are two major advantages of this technique. First, it is capable of retrieving aerosol properties over a wider variety of land surfaces than possible using measurements only in the visible or near-IR because the reflectance of all terrestrial surfaces (not covered with snow) is small in the UV. Secondly, the technique is capable of retrieving aerosol absorption due to the strong interaction between aerosol absorption and the molecular scattering from below the aerosol layer.

The OMAERUV algorithm uses pre-computed TOA reflectances for a set of 21 assumed aerosol models to retrieve AOD and AAOD. The set of aerosol models is composed of three major aerosol types: desert dust, carbonaceous aerosols from biomass burning, and weakly absorbing aerosols. Each type includes seven models with different SSAs. The aerosol size distribution functions are based on the long-term data set of measurements by AERONET. The retrieval algorithm is sensitive to aerosol height, so AOD and AAOD results are archived in the HDF data file for five different assumptions for the altitude of the aerosol. Separate Scientific Data Set (SDS) parameters giving the best solution values of AOD and AAOD from among the five are also provided. In this paper, we use only these best solution SDS values for the highest quality (SDS "AlgorithmFlags" $=0$ ) retrievals. OMAERUV results are reported not only at $388 \mathrm{~nm}$, which is the primary retrieval wavelength, but also at 354 and $500 \mathrm{~nm}$ to allow comparison with measurements from other sensors and with model calculations. However, Torres et al. (2007) emphasize that results reported at 354 and $500 \mathrm{~nm}$, and especially those at $500 \mathrm{~nm}$, should be considered less reliable because the transformation necessary to calculate those values increases the dependence of the retrieval on the assumed aerosol model. The relatively large size of the OMI pixel makes results susceptible to sub-pixel cloud contamination, and such cloud-contamination can lead to overestimation of AOD and underestimation of the single scattering co-albedo (Torres et al., 1998, 2007). However, due to a cancellation of these two effects in the calculation of AAOD, this quantity is less sensitive to sub-pixel cloud contamination and, hence, is considered the more reliable OMI aerosol product (Torres et al., 2007).

The OMAERO algorithm (Torres et al., 2002) is a multiwavelength optimal estimation technique for retrieving AOD from OMI TOA reflectances judged to be cloud-free. The approach used in the algorithm is to try to derive as much aerosol information as possible from the OMI spectra, thus giving the algorithm the freedom to choose among aerosol models. In the current setup of the algorithm, data from 14 wavelength bands between 342.5 and $483.5 \mathrm{~nm}$ are used (Curier et al., 2008). OMAERO uses forward calculations of TOA reflectances for a wide variety of microphysical aerosol models representative of desert dust, biomass burning, volcanic and weakly absorbing aerosol types. The various models differ by size distribution, refractive index, and aerosol layer height. As a constraint on the retrieval, in the current implementation of the algorithm, major aerosol types are preselected on the basis of a climatology of aerosol geographical distribution generated by a chemical transport model as described by Curier et al. (2008). It is noted that more than one major type can be selected for a specific location and 
time of year to give the algorithm the freedom to choose, for example, between biomass burning and weakly absorbing aerosol models. Using non-linear least squares methodology, the best-fitting aerosol model is found by minimizing the sum (over wavelength) of the squares of error-weighted differences between wavelength-dependent measured TOA reflectances and wavelength- and AOD-dependent model reflectances. In addition to the best-fitting aerosol model, the values of AOD, SSA, size distribution and aerosol height that are associated with the best fit aerosol model are provided in the archived OMAERO Level 2 data files. In addition, the files provide retrieval results for up to ten of all those aerosol models for which the root mean square of the residual reflectance falls below a given threshold $\left(3 \times 10^{-3}\right)$. These include the aerosol models together with their associated values of AOD and SSA, and the mean and standard deviation of the AODs and SSAs for all retrievals satisfying the threshold criterion. The surface reflectance is prescribed using a climatology based on MISR (Curier et al., 2008). Over the ocean the full bi-directional surface reflectance (BRDF) is taken into account, and it is modeled as a function of wind speed and chlorophyll concentration. Curier et al. concluded that the current land surface albedo climatology contains obvious shortcomings, and work is ongoing to replace this database with one derived from OMI (Kleipool et al., 2008).

\subsection{MODIS}

MODIS is a scanning spectroradiometer with 36 visible, near-infrared, and infrared spectral bands between 0.553 and $14.235 \mu \mathrm{m}$ (King et al., 1992). There are two MODIS instruments currently in operation: one on Terra, which was launched in December 1999, and one on Aqua, which was launched in May 2002. In this paper, we include AODs archived in the MODIS Aqua MYD04_L2 Version 005 aerosol data set, in which AOD spectra are provided for nominal (at nadir view) 10 by $10 \mathrm{~km}^{2}$ pixels at wavelengths 466 , $553,644,855,1243,1632$ and $2119 \mathrm{~nm}$ over the ocean, and at wavelengths 470,660 , and $2120 \mathrm{~nm}$ over land. For each pixel for which a spectral AOD has been retrieved, the archive data file also provides an estimate of the fraction of the pixel covered by clouds, as described below.

The MODIS over-ocean operational algorithm for the retrieval of AOD has been described in detail by Remer et al. (2005), and the over-land algorithm has been described by Remer et al. (2005) and Levy et al. (2007). The overocean algorithm aggregates reflectances from the six channels between 553 and $2119 \mathrm{~nm}$ into nominal 10 by $10 \mathrm{~km}^{2}$ pixels each composed of 20 by 20 pixels at $500 \mathrm{~m}$ resolution. The algorithm uses the difference in spatial variability between aerosols and clouds for the identification of clouds (Martins et al., 2002). Specifically, the standard deviation of $553-\mathrm{nm}$ reflectances of a square set of 3 by 3500-m pixels is compared to a threshold value of 0.0025 . If the standard deviation is larger than the threshold value the center pixel is declared "cloudy" and the set of $3 \times 3$ pixels is moved in such a way that a pixel neighboring the previous center pixel becomes the new center pixel. The result is a cloud mask at an effective resolution of $500 \mathrm{~m}$. The fraction of "cloudy" 500 by $500 \mathrm{~m}^{2}$ pixels within the 10 by $10 \mathrm{~km}^{2}$ pixel is archived in the level-2 data file for each large pixel for which an AOD is retrieved. This test separates aerosol from most cloud types, but may fail for large, thick clouds and for cirrus, which can be spatially homogeneous. It may also erroneously identify inhomogeneous aerosol fields as clouds. After the application of various cloud masks, a sediment mask is applied ( $\mathrm{Li}$ et al., 2003), after which the brightest $25 \%$ and darkest $25 \%$ (at $855 \mathrm{~nm}$ ) of the remaining pixels are discarded. The reflectances in the remaining pixels are averaged and compared to a look-up table consisting of four fine and five coarse mode aerosol types (Remer et al., 2005). All combinations of fine and coarse mode pairs that fit the measured reflectances to within 3\% (or the best three combinations if no solution fits the reflectances to within 3\%) are then averaged to yield the average combination of fine and coarse mode aerosol.

\subsection{AATS-14}

The AATS-14 instrument has been described in detail in several previous publications (e.g. Russell et al., 2005, 2007; Livingston et al., 2007; and references therein), so we provide only a brief synopsis here. The instrument measures the atmospheric transmission of the direct solar beam in 14 spectral channels with center wavelengths, $\lambda$, ranging from 354 to $2139 \mathrm{~nm}$ and bandwidths of $\sim 5 \mathrm{~nm}$ (exceptions are $2.0 \mathrm{~nm}$ for the 354-nm channel and $17.3 \mathrm{~nm}$ for the $2139-\mathrm{nm}$ channel). Azimuth and elevation motors rotate a tracking head to lock on to the solar beam and maintain detectors normal to it. During MILAGRO/INTEX-B, the AATS was mounted on the J31 in the same configuration (Russell et al., 2007) as used during the 2004 INTEX-A/Intercontinental Transport and Chemical Transformation (ITCT) field deployment.

The AATS channel wavelengths have been chosen to permit separation of aerosol, water vapor, and ozone transmission along the AATS-to-Sun slant path. Our methods for data acquisition, reduction, calibration, and error analysis have been well documented in the literature (Russell et al., 1993a, b; Schmid and Wehrli, 1995; Schmid et al., 1996, 1998, 2001, 2003b; Livingston et al., 2005, 2007) and are not repeated here. AODs are calculated from detector voltages measured in 13 channels, with the channels centered at $940 \mathrm{~nm}$ and neighboring wavelengths used for calculation of CWV. Calculation of $\operatorname{AOD}(\lambda)$, where is the AATS channel center wavelength, and CWV requires knowledge of exoatmospheric detector voltages, $\mathrm{V}_{0}(\lambda)$. These were calculated from analysis of sunrise measurements acquired at Mauna Loa Observatory (MLO), Hawaii, before (January 2006) and after (May 2006) the MILAGRO deployment and, following the procedure described in Schmid et al. (2003a, b), by analysis of high altitude clear air AOD spectra obtained during 
the deployment. Specifically, the $\mathrm{V}_{0}$ values were derived using the Langley plot technique (e.g. Russell et al., 1993a, b; Schmid and Wehrli, 1995) for all channels except $940 \mathrm{~nm}$, for which a modified Langley technique (Reagan et al., 1995; Michalsky et al., 1995; Schmid et al., 1996, 2001) was employed to account for water vapor absorption. Analysis of the high altitude AOD spectra involved calculating the best-fit second order polynomial of $\log (\operatorname{AOD}(\lambda))$ vs. $\log (\lambda)$ to insure positive values of $\operatorname{AOD}(\lambda)$ and a "smooth" variation with wavelength. The residuals between the $\operatorname{AOD}(\lambda)$ calculated from the best fit polynomial and the $\operatorname{AOD}(\lambda)$ calculated from the MLO $V_{0}$ values were then used to calculate small correction factors to be applied to the MLO $V_{0}$ values. In fact, the mean $\mathrm{V}_{0}$ values derived from the two MLO data sets agreed to better than $0.5 \%$ in 10 of the 13 AOD channels, with differences of $0.86 \%$ and $0.76 \%$ for the $380-\mathrm{nm}$ and $1558-\mathrm{nm}$ channels, respectively, and a difference of $2.58 \%$ for the 778 $\mathrm{nm}$ channel. Because of the good agreement between the two MLO data sets for most channels, it was decided to apply the results of the high altitude AOD spectral fits to the January 2006 MLO values of $\mathrm{V}_{0}$ and use these adjusted values in the analysis of the MILAGRO data. The statistical component of the uncertainty in $\mathrm{V}_{0}$ was set equal to $50 \%$ of the mean difference between the January and May MLO results.

\subsection{SSFR}

The Solar Spectral Flux Radiometer (SSFR) (Pilewskie et al., 2003) is a moderate resolution $(8-12 \mathrm{~nm})$ spectrometer that spans the wavelength range $350-2100 \mathrm{~nm}$. It consists of upward and downward looking sensors that were mounted on the J31 during MILAGRO/INTEX-B and provided coincident measurements of upwelling and downwelling spectral irradiance. Coddington et al. (2008) have shown that SSFR measurements can be combined with other airborne and ground-based atmospheric measurements to yield spectral surface albedo, and they have applied this methodology to the MILAGRO data set. In this paper, we use SSFR retrievals of spectral surface albedo for J31 data acquired over Mexico City on 19 March for comparison to OMAERO assumptions of terrain reflectivity. We also use the SSFR data with the AATS data to derive the SSA and AAOD on 19 March (Bergstrom et al., 2009).

\subsection{AERONET}

AERONET is a global network of ground-based automatic tracking sun/sky radiometers (Holben et al., 1998). Data from these instruments are analyzed to yield spectral AOD, CWV, aerosol size distribution, and SSA (Holben et al., 1998, 2001; Eck et al., 2001; Dubovik et al., 2000, 2002), which are archived after application of cloud screening and quality control procedures described by Smirnov et al. (2000). In this paper, we use data obtained at three AERONET sites in the Mexico City area: the T0 supersite

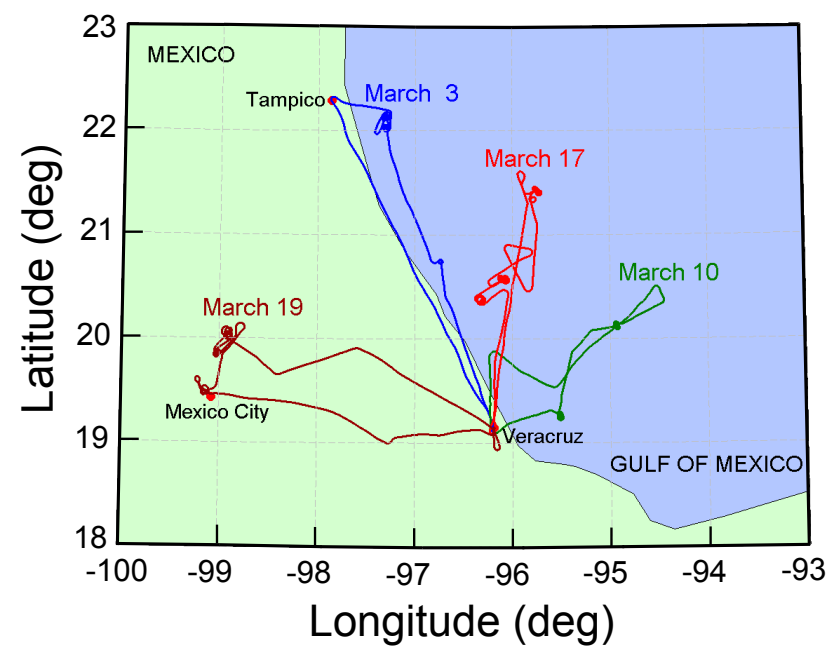

Fig. 1. Map view of the four J31 flight tracks coincident with OMI overpasses during MILAGRO.

$\left(19.49^{\circ} \mathrm{N}, 99.15^{\circ} \mathrm{W}\right.$ ) located at IMP (Instituto Mexicano del Petroleo) about $9 \mathrm{~km}$ west-northwest of the Mexico City International Airport, and the $\mathrm{T} 1\left(19.70^{\circ} \mathrm{N}, 98.98^{\circ} \mathrm{W}\right)$ and $\mathrm{T} 2$ $\left(20.01^{\circ} \mathrm{N}, 98.91^{\circ} \mathrm{W}\right)$ non-urban sites located approximately 30 and $63 \mathrm{~km}$, respectively, northeast of T0.

\section{Results}

\subsection{Overview of MILAGRO data cases}

The J31 made 13 science flights originating from its base in Veracruz, Mexico during the MILAGRO/INTEX-B study. Nine of these were primarily just offshore over the Gulf of Mexico, and four were inland over the Mexico City megalopolis. Four of the 13 flights included Aura overpasses for which OMI and AATS AOD spectra have been retrieved at coincident or near-coincident times and locations. As shown in Fig. 1, three of these (3, 10, and 17 March) were over the Gulf of Mexico, and one (19 March) was over the Mexico City area. AOD retrievals from near-coincident AquaMODIS measurements are available for the 10 and 17 March cases, but not for the 3 March case because the MODIS pixels along the J31 flight track were in sun glint.

\subsection{March 2006}

The 10 March J31 science flight included a low altitude horizontal transect over the Gulf of Mexico timed to coincide with the Aqua overpass at 19:58 UT. The Aura overpass occurred at 20:13 UT. Figure 2a displays the Aqua-MODIS true color image acquired during the satellite overpass and the J31 flight track color-coded by aircraft GPS altitude. The J31 flew from SW to NE at $60 \mathrm{~m}$ above sea level (a.s.l.) during the period 19:40-20:01 UT, and this portion of the track is 
colored cyan. Figure $2 \mathrm{~b}$ superimposes this segment of the J31 flight track on the OMAERUV, OMAERO and MODIS retrieval pixels that intersect the track. As indicated by the time callouts along the track, the J31 was at the northeast portion of this transect at the time of Aqua overpass. The pixel geo-registration values for the OMAERUV and OMAERO retrievals differ slightly because the OMAERUV retrieval uses the visible (VIS) channel and the OMAERO retrieval uses the UV-2 channel of the OMI sensor to calculate these values. Hence, corresponding OMI pixels are outlined with the same color but different line styles (OMAERUV-solid, OMAERO-dashed) in this paper. This difference in georegistration has no significant effect on the results presented in this paper, but it does mildly complicate the analyses to the extent that sometimes slightly different segments of the J31 flight track (and, hence, the AATS measurements) intersect the corresponding OMAERUV and OMAERO retrieval pixels.

There was no OMAERO retrieval corresponding to the OMAERUV retrieval within the dark green pixel centered at $19.89^{\circ} \mathrm{N}, 95.51^{\circ} \mathrm{W}$ in Fig. $2 \mathrm{~b}$ due to extensive clouds, and this brings into question the validity of the OMAERUV retrieval within that pixel. The best measure of clouds available to these analyses is the MODIS cloud fraction, which is a product of the MODIS aerosol retrieval algorithm. It equals the fraction of "cloudy" $500 \times 500 \mathrm{~m}^{2}$ pixels within the nominal MODIS $10 \times 10 \mathrm{~km}^{2}$ pixel, where the "cloudy" designation is derived from the MODIS cloud-screening algorithm that takes into account spatial variability (Martins et al., 2002). This parameter is only available for those MODIS pixels for which an AOD retrieval is performed. In Fig. 2b, all MODIS pixels with a non-zero cloud fraction have been shaded grey, and the percent cloud is listed at the center of each of those pixels. Those pixels with no MODIS AOD retrieval because of extensive cloudiness are shown with grey hatching. Consistent with the MODIS true color image shown in Fig. 2a, the southern portion of the measurement region was cloud-free, whereas clouds dominated the northwest region. Figure 2c plots AATS-14 AODs measured along the J31 low altitude transect. AATS measured a small but distinct AOD gradient $(\sim 0.05$ in the midvisible) increasing from $\mathrm{S}$ to $\mathrm{N}$ in the cloud-free region south of $19.8^{\circ} \mathrm{N}$ from 19.68 to $19.82 \mathrm{UT}$, and then a decreasing gradient along the $\mathrm{W}$ to $\mathrm{E}$ portion of the track from 19:95 to 20:02 UT.

Before comparing AATS and OMI AOD retrievals along the J31 low altitude flight segment, we assess the degree of agreement between the AATS and MODIS retrievals. As shown in Fig. 2b, the J31 transect intersected 13 MODIS pixels. Figure 3 compares the MODIS AOD retrieval and the mean AATS AOD spectrum calculated within each of these pixels. Error bars depicting the standard MODIS overwater AOD uncertainty estimate (Remer et al., 2005) of $\pm(0.03+0.05 \times \mathrm{AOD})$ are included, but no AATS measurement uncertainties or standard deviations within each pixel
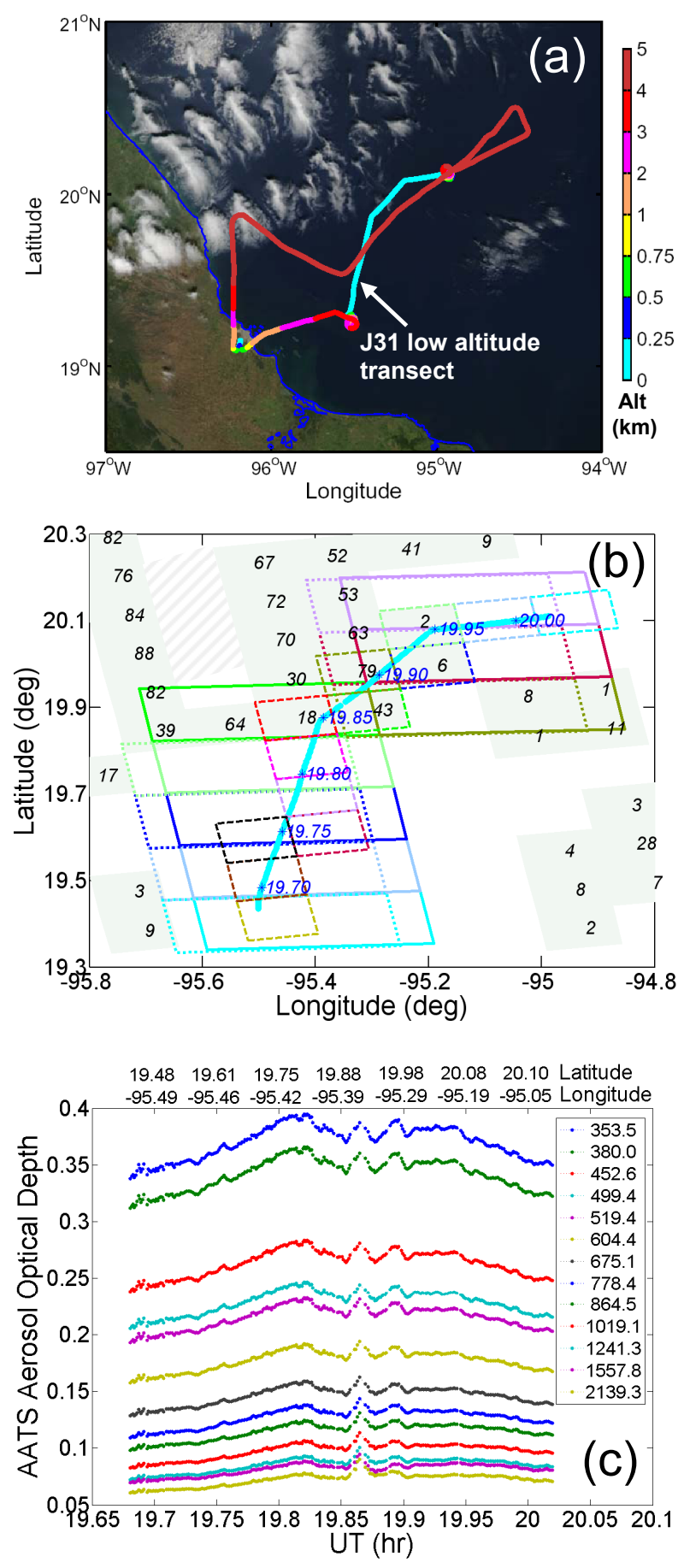

Fig. 2. Case study for 10 March: (a) Aqua-MODIS true color image with superimposed J31 flight track color-coded by altitude; (b) plan view of the J31 low altitude flight track and intersecting OMI (OMAERUV solid, OMAERO dotted) and MODIS (dashed) pixels, with all nonzero MODIS cloud percentages and with times (UT) along the flight track; (c) AOD (color-coded by wavelength given in the legend in $\mathrm{nm}$ ) measured by AATS along the low altitude J31 flight track. 


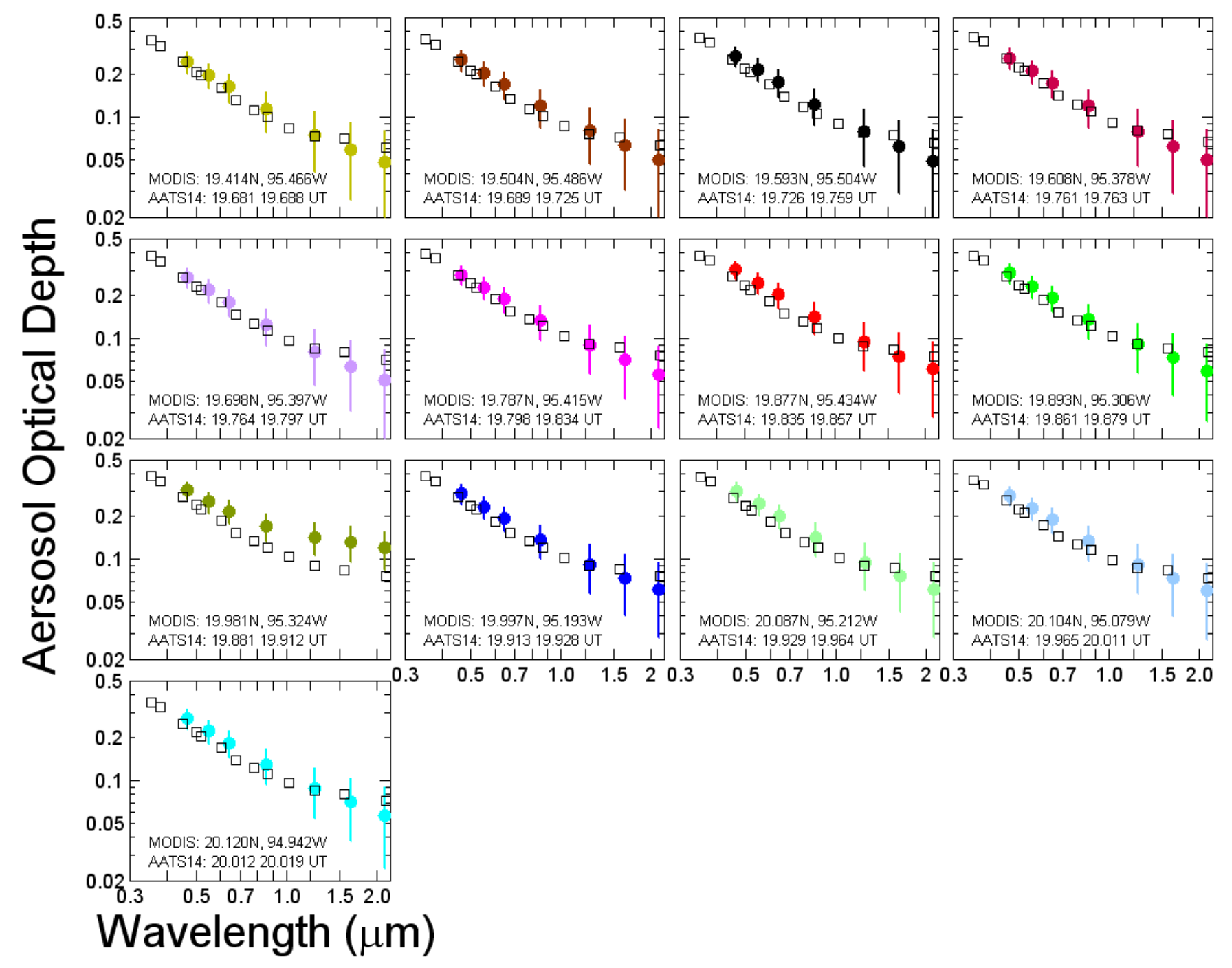

Fig. 3. Comparison of AATS (open black squares) and MODIS (filled colored circles with error bars) AOD spectra within MODIS pixels along the J31 low altitude flight track on 10 March. The color scheme used to plot the MODIS spectra is the same as that used in Fig. $2 \mathrm{~b}$ to plot the locations of the MODIS pixels. No error bars are shown on the AATS data points because the measurement uncertainties and/or the standard deviations within a particular MODIS pixel are smaller than the square symbols.

are shown because these are smaller than the symbols used to plot the AATS AODs. The agreement between AATS and MODIS AODs is well within MODIS uncertainty bars for all pixels except that centered at $19.98^{\circ} \mathrm{N}, 95.32^{\circ} \mathrm{W}$ (olive color), for which the MODIS spectrum exceeds the AATS spectrum at all wavelengths. Since this is the intersecting MODIS pixel with the largest cloud fraction (79\%), it raises the question whether this MODIS retrieval is, in fact, cloud-contaminated. Figure 4 is a scatterplot of MODIS vs. AATS AOD, where the AATS values have been interpolated to MODIS wavelengths and the AODs in the pixel with the largest cloud fraction have been highlighted with larger concentric circles. Except for values from this pixel, all AODs fall within the MODIS AOD uncertainty estimates given above. MODIS-minus-AATS AOD bias and rms differences that exclude values from this pixel are listed on the plot. MODIS AODs at 466, 553, 644 and $855 \mathrm{~nm}$ show a slight positive bias ( 0.015 to 0.027$)$, and the 1632 and $2119 \mathrm{~nm}$ values show a slight negative bias $(-0.010$ to $-0.016)$.

Figure 5a compares AOD spectra retrieved from AATS, OMI, and MODIS using the same pixel color scheme shown in Fig. 2b. The mean AATS AOD spectrum along the lowlevel transect is plotted together with three sets of vertical bars representing the uncertainty (narrowest ticks), standard deviation (medium width ticks), and range (widest ticks) 


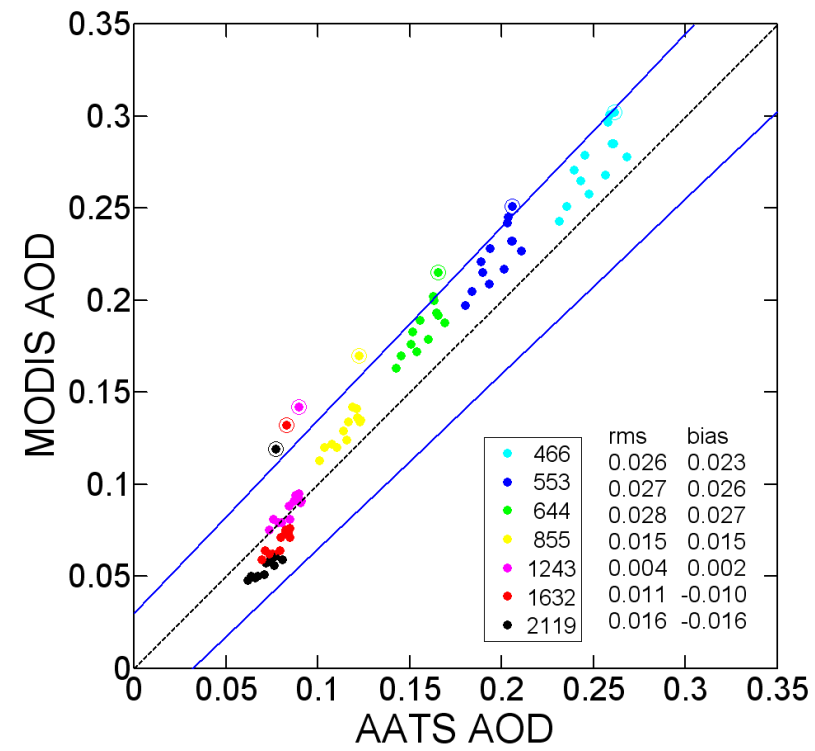

Fig. 4. Scatterplot of MODIS vs. AATS AOD within the pixels along the J31 low altitude flight track on 10 March. AATS values have been interpolated to the MODIS wavelengths, and AODs within the olive-colored MODIS pixel in Fig. $2 b$ (color code shown in $\mathrm{nm}$ in legend) have been emphasized with large concentric circles. The black dashed line gives the one-to-one correspondence, and the two blue lines delineate the expected MODIS AOD uncertainty of $\pm(0.03+0.05 \times \mathrm{AOD})$. RMS and bias values omit the olivecolored pixel.

of AODs along the transect. We have already shown that AATS and MODIS spectral AODs agree within MODIS uncertainty bars except for the olive MODIS pixel. Two sets of OMAERO retrieval results are shown: the archived Collection 3 best-fit spectra, and results from a special run in which only weakly absorbing aerosol models (refractive index 1.4-5.0e-08i) were included in the set of allowable models. Figure 5a shows clearly that the OMAERUV retrievals are significantly less than the AATS AODs and that the archived OMAERO retrievals significantly exceed AATS values. The magnitudes of the constrained OMAERO retrievals agree much better with AATS AODs, but the spectral shapes are much flatter, as discussed further below. The only OMAERUV retrieval close to the mean AATS spectrum is that for the dark green OMAERUV pixel, for which there is no corresponding OMAERO retrieval. Based on the large MODIS cloud fractions for MODIS pixels intersecting this OMI pixel, we believe this OMAERUV retrieval is cloud-contaminated. All OMAERUV retrievals correspond to a non-absorbing sulfate aerosol model with a refractive index of 1.40-0i, and all archived OMAERO best-fit retrievals correspond to one of two carbonaceous (biomass-burning) aerosol models, each with a refractive index of 1.50-0.03i.

Table 1 lists various parameters associated with OMI and AATS retrievals for each intersecting pixel for each of the
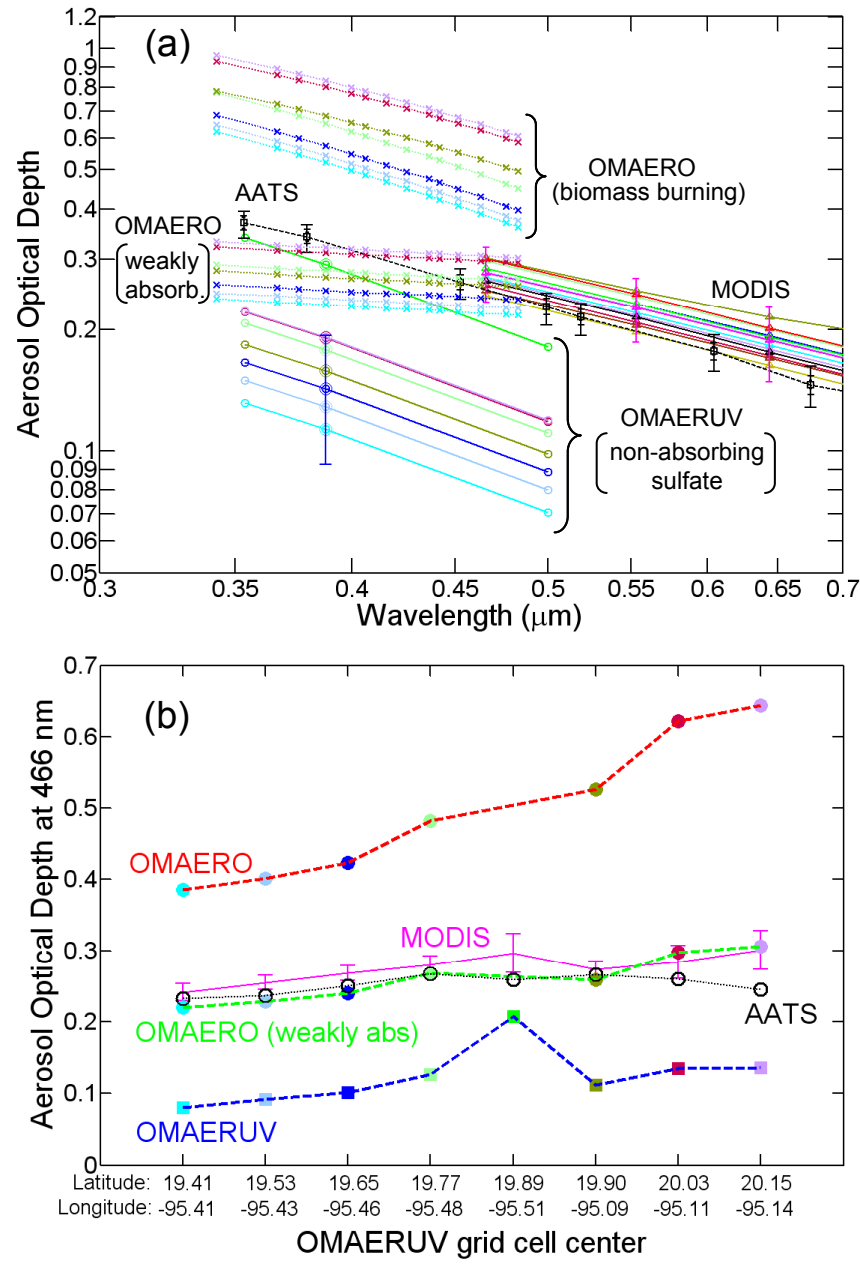

Fig. 5. For 10 March: (a) AOD spectra retrieved by OMAERO (x symbols with dashed lines), OMAERUV (circles with solid lines), MODIS (triangles with solid lines), and AATS (squares with short dashed line). The color scheme is the same as that used in Figs. 2b and 3. The AOD at the primary OMAERUV retrieval wavelength of $388 \mathrm{~nm}$ is emphasized with concentric circles. For OMAERUV and MODIS, vertical bars give representative uncertainties. For AATS, vertical bars give the AOD measurement uncertainty (narrow ticks), standard deviation (medium width ticks) and range (wide ticks) along the track. Two sets of OMAERO results are plotted: the archived retrievals that yield biomass-burning aerosol models, and a special run constrained to retrieve only weakly absorbing aerosol models. (b) Variation of AOD at $466 \mathrm{~nm}$ as a function of OMAERUV pixel, where AATS and OMI values have been interpolated to $466 \mathrm{~nm}$. Vertical bars on the MODIS data give the range of MODIS retrievals for all MODIS pixels intersecting the OMAERUV pixel.

four AATS/OMI coincident events. Among these parameters is the Ångström exponent, $\alpha$, which we calculate using least squares fits. For comparison to OMI values, the AATS $\alpha$ for each pixel was derived from the mean AATS AOD spectrum for all cloud-free measurements within that pixel using only data from the five AATS channels centered at wavelengths 
Table 1. Dates, colors, locations, and selected aerosol retrieval parameters for OMI pixels.

\begin{tabular}{|c|c|c|c|c|c|c|c|c|c|c|c|}
\hline \multirow{2}{*}{$\begin{array}{l}\text { OMI } \\
\text { Retrieval }\end{array}$} & \multirow[b]{2}{*}{ Date } & \multirow{2}{*}{$\begin{array}{l}\text { Pixel } \\
\text { Color }\end{array}$} & \multirow{2}{*}{$\begin{array}{l}\text { Latitude } \\
\text { [deg] }\end{array}$} & \multirow{2}{*}{$\begin{array}{l}\text { Longitude } \\
\text { [deg] }\end{array}$} & \multicolumn{2}{|c|}{ Ångström Exp, $\alpha$} & \multicolumn{2}{|c|}{$\mathrm{AOD}^{1}$} & \multirow{2}{*}{$\begin{array}{l}\text { Aerosol } \\
\text { Model }^{2}\end{array}$} & \multirow{2}{*}{$\begin{array}{l}\text { SSA } \\
(388 \mathrm{~nm})\end{array}$} & \multirow{2}{*}{$\begin{array}{l}\mathrm{Z}_{\text {layer }}^{3} \\
{[\mathrm{~km}]}\end{array}$} \\
\hline & & & & & OMI & AATS & OMI & AATS & & & \\
\hline \multirow[t]{5}{*}{ OMAERUV } & \multirow[t]{5}{*}{$3 \mathrm{Mar}$} & cyan & 21.381 & -97.163 & 1.824 & 1.067 & 0.325 & 0.370 & 3 & 1.000 & 0.0 \\
\hline & & light blue & 21.502 & -97.189 & 1.824 & 1.054 & 0.313 & 0.368 & 3 & 1.000 & 0.0 \\
\hline & & dark blue & 21.623 & -97.215 & 1.824 & 0.965 & 0.316 & 0.394 & 3 & 1.000 & 0.0 \\
\hline & & light green & 21.744 & -97.241 & 1.824 & 1.087 & 0.293 & 0.344 & 3 & 1.000 & 0.0 \\
\hline & & dark green & 21.864 & -97.268 & 1.824 & 1.166 & 0.276 & 0.286 & 3 & 1.000 & 0.0 \\
\hline \multirow[t]{5}{*}{ OMAERO } & \multirow[t]{5}{*}{$3 \mathrm{Mar}$} & cyan & 21.382 & -97.194 & 0.742 & 1.070 & 0.929 & 0.370 & 2313 & 0.851 & $0-2$ \\
\hline & & light blue & 21.503 & -97.221 & 0.743 & 1.052 & 0.884 & 0.368 & 2313 & 0.851 & $0-2$ \\
\hline & & dark blue & 21.624 & -97.247 & 1.351 & 0.965 & 0.701 & 0.394 & 2312 & 0.857 & $0-2$ \\
\hline & & light green & 21.744 & -97.273 & 1.602 & 1.088 & 0.502 & 0.343 & 2311 & 0.852 & $0-2$ \\
\hline & & dark green & 21.865 & -97.300 & 1.393 & 1.167 & 0.393 & 0.285 & 2212 & 0.898 & $0-2$ \\
\hline \multirow[t]{8}{*}{ OMAERUV } & \multirow[t]{8}{*}{$10 \mathrm{Mar}$} & cyan & 19.408 & -95.411 & 1.824 & 1.473 & 0.113 & 0.317 & 3 & 1.000 & 0.0 \\
\hline & & light blue & 19.528 & -95.434 & 1.824 & 1.467 & 0.129 & 0.323 & 3 & 1.000 & 0.0 \\
\hline & & dark blue & 19.649 & -95.458 & 1.824 & 1.444 & 0.143 & 0.340 & 3 & 1.000 & 0.0 \\
\hline & & light green & 19.770 & -95.482 & 1.824 & 1.411 & 0.179 & 0.360 & 3 & 1.000 & 0.0 \\
\hline & & dark green & 19.891 & -95.506 & 1.824 & 1.413 & 0.292 & 0.350 & 3 & 1.000 & 0.0 \\
\hline & & olive & 19.905 & -95.090 & 1.824 & 1.402 & 0.158 & 0.358 & 3 & 1.000 & 0.0 \\
\hline & & maroon & 20.026 & -95.113 & 1.824 & 1.421 & 0.191 & 0.351 & 3 & 1.000 & 0.0 \\
\hline & & violet & 20.146 & -95.137 & 1.824 & 1.425 & 0.192 & 0.331 & 3 & 1.000 & 0.0 \\
\hline \multirow[t]{7}{*}{ OMAERO } & \multirow[t]{7}{*}{$10 \mathrm{Mar}$} & cyan & 19.402 & -95.467 & 1.600 & 1.474 & 0.522 & 0.317 & 2311 & 0.852 & $0-2$ \\
\hline & & light blue & 19.522 & -95.491 & 1.601 & 1.467 & 0.543 & 0.323 & 2311 & 0.852 & $0-2$ \\
\hline & & dark blue & 19.643 & -95.515 & 1.602 & 1.446 & 0.574 & 0.339 & 2311 & 0.852 & $0-2$ \\
\hline & & light green & 19.764 & -95.539 & 1.600 & 1.411 & 0.652 & 0.360 & 2311 & 0.852 & $0-2$ \\
\hline & & olive & 19.900 & -95.152 & 1.349 & 1.409 & 0.681 & 0.349 & 2312 & 0.857 & $0-2$ \\
\hline & & maroon & 20.021 & -95.175 & 1.350 & 1.421 & 0.805 & 0.353 & 2312 & 0.857 & $0-2$ \\
\hline & & violet & 20.141 & -95.199 & 1.349 & 1.425 & 0.833 & 0.333 & 2312 & 0.857 & $0-2$ \\
\hline \multirow[t]{7}{*}{ OMAERO $^{4}$} & $10 \mathrm{Mar}$ & cyan & 19.402 & -95.467 & 0.264 & 1.474 & 0.231 & 0.317 & 1114 & 1.000 & $0-2$ \\
\hline & & light blue & 19.522 & -95.491 & 0.259 & 1.467 & 0.239 & 0.323 & 1114 & 1.000 & $0-2$ \\
\hline & & dark blue & 19.643 & -95.515 & 0.257 & 1.446 & 0.251 & 0.339 & 1114 & 1.000 & $0-2$ \\
\hline & & light green & 19.764 & -95.539 & 0.257 & 1.411 & 0.281 & 0.360 & 1114 & 1.000 & $0-2$ \\
\hline & & olive & 19.900 & -95.152 & 0.258 & 1.409 & 0.271 & 0.349 & 1114 & 1.000 & $0-2$ \\
\hline & & maroon & 20.021 & -95.175 & 0.259 & 1.421 & 0.312 & 0.353 & 1114 & 1.000 & $0-2$ \\
\hline & & violet & 20.141 & -95.199 & 0.265 & 1.425 & 0.321 & 0.333 & 1114 & 1.000 & $0-2$ \\
\hline OMAERUV & $17 \mathrm{Mar}$ & cyan & 20.467 & -96.290 & 1.824 & 1.257 & 0.226 & 0.290 & 3 & 1.000 & 0.0 \\
\hline & & light blue & 20.588 & -96.313 & 1.824 & 1.241 & 0.217 & 0.274 & 3 & 1.000 & 0.0 \\
\hline OMAERO & 17 Mar & cyan & 20.464 & -96.359 & 0.266 & 1.257 & 0.279 & 0.291 & 1114 & 1.000 & $0-2$ \\
\hline & & light blue & 20.585 & -96.382 & 0.261 & 1.251 & 0.271 & 0.270 & 1114 & 1.000 & $0-2$ \\
\hline & & dark blue & 20.598 & -95.897 & 0.764 & 1.234 & 0.742 & 0.277 & 2213 & 0.893 & $0-2$ \\
\hline OMAERUV & 19 Mar, T2 & cyan & 19.834 & -99.009 & 0.606 & 0.117 & 0.692 & 0.280 & 2 & 0.896 & 4.1 \\
\hline & & light blue & 19.954 & -99.036 & 0.606 & 0.147 & 0.698 & 0.213 & 2 & 0.900 & 4.1 \\
\hline & & dark blue & 19.985 & -98.813 & 0.606 & 0.211 & 0.545 & 0.200 & 2 & 0.890 & 4.0 \\
\hline OMAERO & 19 Mar, T2 & cyan & 19.849 & -99.028 & 1.602 & 0.117 & 2.977 & 0.288 & 2321 & 0.852 & $2-4$ \\
\hline & & dark blue & 19.999 & -98.834 & 0.763 & 0.232 & 2.144 & 0.198 & 2233 & 0.893 & $4-6$ \\
\hline OMAERUV & 19 Mar, T0 & cyan & 19.439 & -99.147 & 0.606 & - & 0.578 & - & 2 & 0.888 & 4.1 \\
\hline & & light blue & 19.560 & -99.175 & 0.606 & 0.644 & 0.572 & 0.284 & 2 & 0.893 & 4.1 \\
\hline & & dark blue & 19.681 & -99.203 & 0.606 & 0.585 & 0.520 & 0.308 & 2 & 0.878 & 4.1 \\
\hline OMAERO & 19 Mar, T0 & cyan & 19.456 & -99.166 & 1.601 & 0.701 & 2.846 & 0.258 & 2331 & 0.852 & $4-6$ \\
\hline & & light blue & 19.576 & -99.193 & 0.764 & 0.631 & 1.679 & 0.290 & 2233 & 0.893 & $4-6$ \\
\hline
\end{tabular}

1 OMI wavelength: $388 \mathrm{~nm}$, AATS wavelength: $380 \mathrm{~nm}$.

2 OMAERUV: 2=dust aerosol, 3=sulfate aerosol. OMAERO: 1114=weakly absorbing aerosol, >2000=biomass-burning aerosol.

3 Altitude of aerosol layer assumed in the retrieval.

${ }^{4}$ OMAERO retrieval restricted to weakly absorbing aerosol models. 
between $353 \mathrm{~nm}$ and $519 \mathrm{~nm}$. For the 10 March comparison, OMAERUV spectra are steeper $\left(\alpha_{\text {OMAERUV }}=1.82\right)$ and archived best-fit OMAERO spectra are slightly steeper $\left(\alpha_{\text {OMAERO }}=1.60\right)$ or slightly flatter $\left(\alpha_{\text {OMAERO }}=1.35\right)$ than the corresponding AATS spectra $\left(\alpha_{\text {AATS }}=1.41-1.47\right)$. The small variation in the OMAERO $\alpha$ values is attributed to the discretization of the aerosol models. With SSA of $\sim 0.85$ at $388 \mathrm{~nm}$, the OMAERO aerosol models yield AAOD (not shown) at $388 \mathrm{~nm}$ of only $0.08-0.12$. The OMAERO spectra constrained to retrieve a weakly absorbing aerosol yield a much flatter wavelength dependence $\left(\alpha_{\mathrm{OMAERO}}=0.26\right)$.

In Fig. 5b, we examine the variation of AOD as a function of OMI pixel along a path from SSW to NNE. For ease in interpretation, the ticks along the abscissa are labeled with the locations of the OMAERUV pixel centers. The data points for the OMI retrievals are color-coded using the same scheme used in Figs. $2 b$ and 5a; the color of the connecting lines is arbitrary and chosen solely to facilitate graph interpretation. All AODs in Fig. 5b are for the shortest MODIS retrieval wavelength, $466 \mathrm{~nm}$, with the AATS and OMI values interpolated to that wavelength. The vertical bars on the MODIS AODs in Fig. 5b delineate the range of all MODIS retrievals in those MODIS pixels intersecting the larger OMAERUV pixel, and the line connects the mean values. Hence, for a particular OMAERUV pixel, the MODIS mean value may include retrievals from one or more MODIS pixels for which part or even most of the pixel falls outside the OMAERUV pixel. It should be noted that the AATS data points are the mean cloud-free values along the J31 track within the OMAERUV pixel and, hence, represent measurements acquired over a much smaller sampling region than that of the OMI retrieval or the MODIS mean value calculated over several MODIS pixels. All retrievals observe the AOD gradient increasing from $\mathrm{S}$ to $\mathrm{N}$ within the region spanned by the four southernmost OMI pixels. MODIS and OMAERUV retrievals exhibit a similar behavior for all OMAERUV pixels, especially if the OMAERUV retrieval within the dark green pixel centered at $19.89^{\circ} \mathrm{N}, 95.51^{\circ} \mathrm{W}$ is ignored due to the high likelihood of cloud contamination, as noted above. The MODIS/OMAERUV data for the remaining seven pixels yield a coefficient of determination, $r^{2}$, of 0.91. The archived OMAERO best-fit retrieval yields AODs that exhibit a significantly larger relative increase than do those retrieved by the MODIS and OMAERUV algorithms in the three northeastern-most OMI pixels. The aerosol model corresponding to the best-fit archived OMAERO retrievals within these pixels differs slightly from the model corresponding to the best-fit result in the other four OMI pixels. Specifically, the latter aerosol size distribution has slightly larger modal radii for the fine and coarse modes and contains slightly more particles in the coarse mode than the former (cf. Table 2; Torres et al., 2007). Results are also shown for the OMAERO retrievals constrained to retrieve a weakly absorbing aerosol, and these exhibit much better agreement with the AATS and MODIS AODs. The correlation between the constrained OMAERO (or the archived OMAERO) and AATS AODs is poor $\left(r^{2}=0.26\right.$ or 0.21 , respectively) if all seven OMAERO retrieval pixels are included, but this is caused by the AATS and OMAERO AOD differences in the two northeastern-most OMAERO pixels. These differences might be due to spatio-temporal sampling differences between AATS and OMI, as discussed above, or to possible cloud contamination in the satellite data. The correlation improves dramatically $\left(r^{2}=0.97\right)$ if these two pixels are omitted, and the result is similar $\left(r^{2}=0.98\right)$ if only the four cloudfree pixels (southwestern-most) are considered. Although the constrained OMAERO AODs are more than double the corresponding OMAERUV values, the pixel-to-pixel AOD behavior is well-correlated $\left(r^{2}=0.95\right)$ with the OMAERUV results, which might be expected since the two algorithms operate on the same radiances.

Next, we examine for each pixel the range of OMAERO solutions that passed the retrieval reflectance threshold test (Sect. 2.1). Figure 6 overplots these spectra for each pixel. The legend lists the RMS reflectance residual value and the corresponding identifier code for the aerosol model for each retrieval. For each pixel, the best-fit (lowest RMS residual) solution is plotted as a solid cyan circle with connecting line; these are the archived spectra shown in Fig. 5. The mean of all solutions satisfying the RMS threshold test is plotted as an open brown circle with a connecting dotted line. For reference, the mean AATS AOD spectrum calculated over the entire low altitude J31 flight track is shown together with vertical bars delineating the range of AODs along the track. For each of the pixels shown, the slope of the best-fit retrieval differs little from that of the corresponding AATS spectrum. In all except the two northernmost pixels, for which only two or three solutions satisfy the RMS threshold criterion, there is one solution that corresponds to the weakly absorbing aerosol model 1114 chosen by the constrained OMAERO retrievals included in Fig. 5. As shown in Fig. 6, the retrievals choosing a biomass burning aerosol model overestimate the AATS AOD, whereas those selecting the weakly absorbing aerosol model show better agreement in AOD. We note that the RMS values for the different aerosol models are nearly equal, which indicates that the information in the OMI spectra in this case is not enough to select the correct aerosol main type. Therefore, instead of relying on the best-fit results, it is preferable to examine the mean and standard deviation over the set of models that passed the RMS threshold test. These mean AODs agree better with the AATS values than the bestfit values. The tendency of OMAERO to choose biomass burning aerosol models for this case (and the other two overwater cases presented below) may be related to shortcomings in the ocean surface reflectance model, and this is still under investigation. 


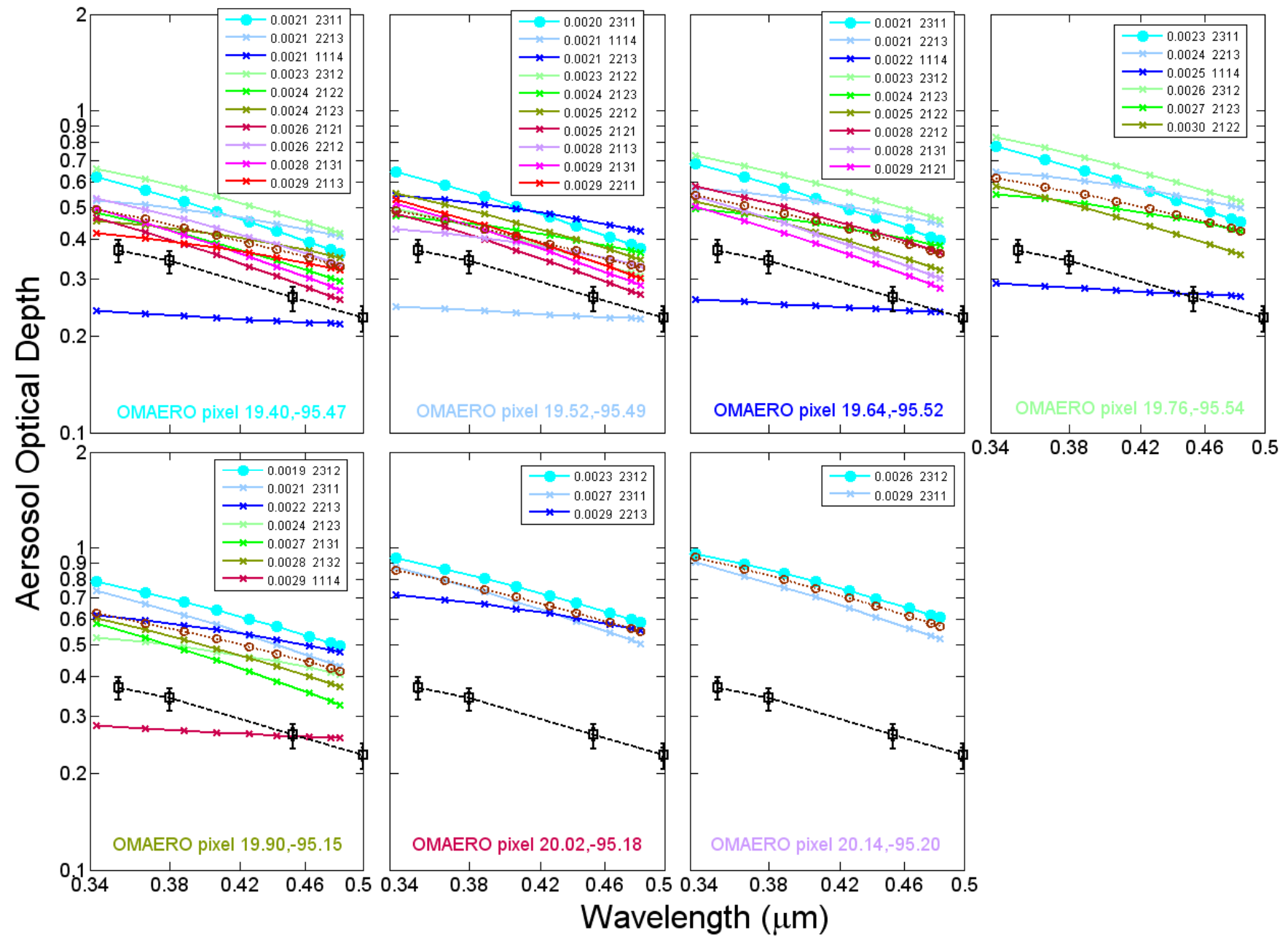

Fig. 6. For 10 March, OMAERO AOD spectra that passed the RMS residual reflectance threshold within each OMAERO pixel. Legends give the RMS value of residual reflectance and the aerosol model code. The best-fit OMAERO solution (smallest RMS residual) is colored cyan, and the brown circles with connecting dotted line represent the mean of all the solutions. For comparison, the mean AATS AOD spectrum along the low altitude flight track is shown with the black squares and dashed line; the vertical bars indicate the range. Latitude and longitude of each OMAERO pixel centerpoint is listed at the bottom of each frame using the same color scheme as that used in Figs. $2 \mathrm{~b}$ and 3.

\subsection{March 2006}

On 3 March, the J31 flew over the Gulf of Mexico during the period 16:36-20:00 UT. Figure 7a shows the J31 flight track superimposed on the Aqua-MODIS 19:50-19:55 UT true color image. AATS obtained measurements during two over-water low altitude horizontal segments during the J31's southbound transit back to Veracruz. The first was 18:50 19:01 UT, and the second was 19:24-19:29 UT. The Aura overpass was 20:07 UT, but OMI AOD retrievals are available only for the earlier J31 low altitude transect due to cloud contamination in the OMI pixels collocated with the later flight segment, as evidenced by the standard MODIS cloud mask product in Fig. 7b. Unfortunately, there are no MODIS aerosol retrievals or cloud fraction data available along the J31 track due to sun glint, as noted in Sect. 3.1.
The 18:50-19:01 UT low altitude (60 m a.s.1.) aircraft segment intersected five OMI pixels, as shown in Fig. 7c. Gaps in the flight track indicate AATS measurements that have been flagged as cloud-contaminated and removed. These same gaps are reflected by missing data in the time trace of AATS AODs shown in Fig. 7d. Most of the cloud occurrences were along the J31 track in the three southernmost OMI pixels, as there were none in the northernmost (dark green) OMI pixel and the northern two-thirds of the adjacent (light green) pixel. It can be seen in Fig. $7 \mathrm{~d}$ that AATS observed an increasing gradient in AOD from $\mathrm{N}$ to $\mathrm{S}$ along the northern half of the low altitude flight segment. The magnitude of this gradient was $\sim 0.10$ in the mid-visible and decreased with wavelength. The OMI AOD retrievals within the three northernmost pixels (dark green, light green, 

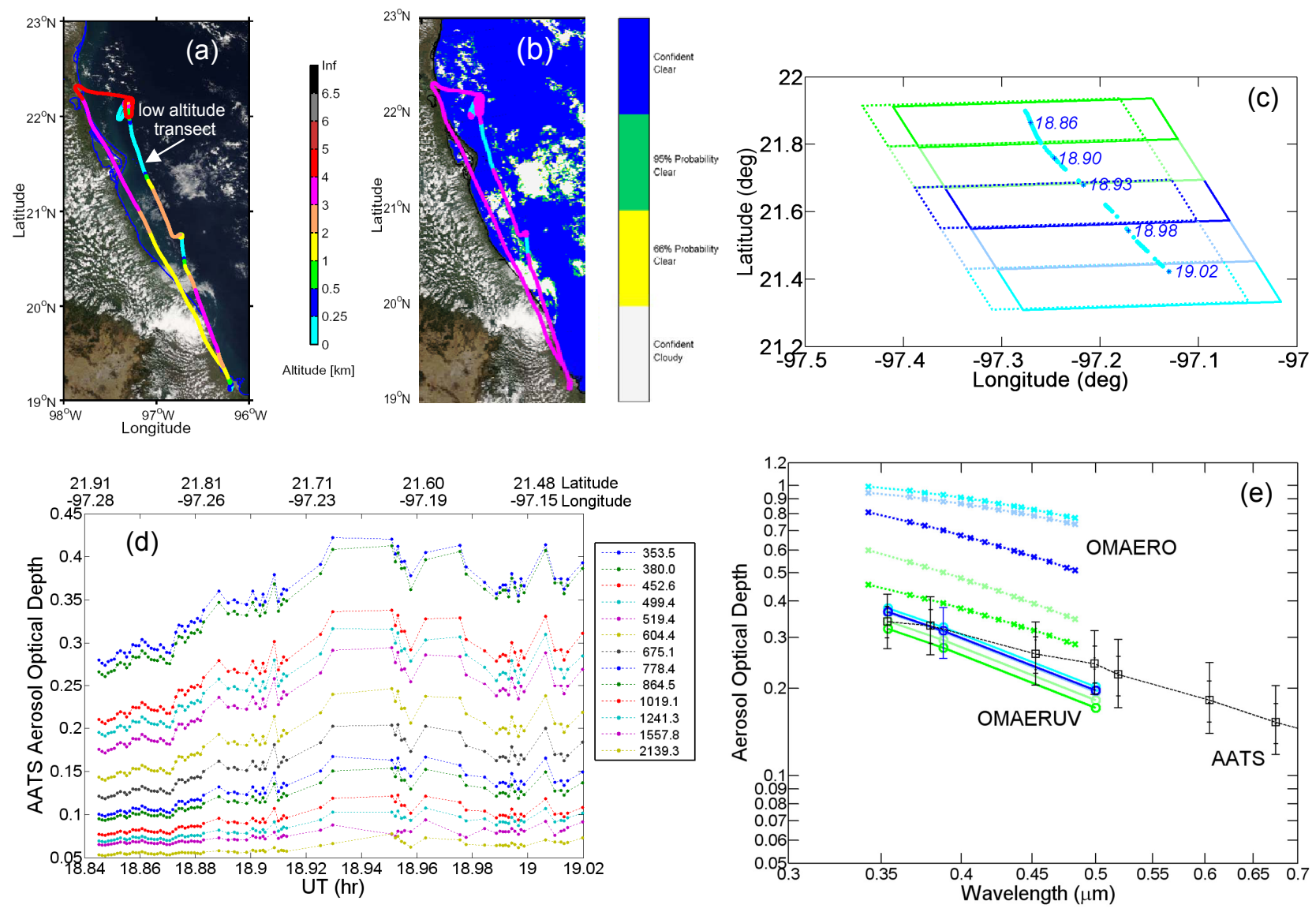

Fig. 7. Case study for 3 March: (a) Aqua MODIS true color image with color-coded J31 flight track; (b) MODIS standard cloud mask product; (c) plan view of the J31 low-altitude flight track and intersecting OMI (OMAERUV solid, OMAERO dotted) pixels, with J31 flight track times; (d) AOD measured by AATS along the low altitude J31 flight track with same color code as in Fig. 2c; (e) AOD spectra retrieved by OMAERO (x symbols with dashed lines), OMAERUV (circles with solid lines), and AATS (squares with short dashed line). The color scheme is the same as in (c). Vertical bars on AATS AODS are described in Fig. 5 caption.

and dark blue) also indicate a gradient, although the gradient magnitudes retrieved by the OMAERO and OMAERUV algorithms differ from that observed by AATS. This is evident in Fig. 7e, which compares the OMI AOD retrievals with the mean AATS AOD spectrum along the low altitude flight segment. In general, the OMAERO AODs significantly exceed the AATS AODs, and the OMAERUV values are slightly less than the AATS values. All OMAERUV retrievals correspond to a non-absorbing sulfate aerosol model, whereas the OMAERO best-fit solutions correspond to a carbonaceous aerosol model, as was the case for the 10 March comparison. No data were available with OMAERO constrained to weakly absorbing aerosol models only. The measured AOD gradient is masked by the mean AATS AOD spectrum plotted in Fig. 7e, although this gradient is consistent with the accompanying vertical bars with wide ticks that delineate the range of AATS AODs.

In Fig. 8 we compare OMI and mean AATS spectra within each OMI pixel. OMAERUV AODs at $354 \mathrm{~nm}$ agree well with the corresponding AATS values, and the OMAERUV AODs at the primary retrieval wavelength of $388 \mathrm{~nm}$ are only slightly less than the corresponding AATS values, which fall within the upper error bar of the OMAERUV AODs for all 5 pixels. However, OMAERO AODs significantly exceed corresponding AATS values in each pixel, and even the OMAERO spectrum with the smallest AODs and smallest AATS-OMI AOD differences (the northernmost dark green pixel for which AATS observed no cloud blockages) overestimates the corresponding mean AATS spectrum within that pixel by $0.1-0.2$. All OMAERUV spectra $\left(\alpha_{\text {OMAERUV }}=1.82\right)$ and the three northernmost OMAERO spectra $\left(\alpha_{\text {OMAERO }}=1.35-1.60\right)$ exhibit a steeper wavelength dependence than do the corresponding AATS spectra $\left(\alpha_{\text {AATS }}=0.96-1.17\right)$. Examination of the archived OMAERO pixel-by-pixel mean AODs (not shown) for all retrievals passing the RMS difference threshold indicates that use of the means would yield little improvement in the comparison between OMAERO and AATS AODs. 

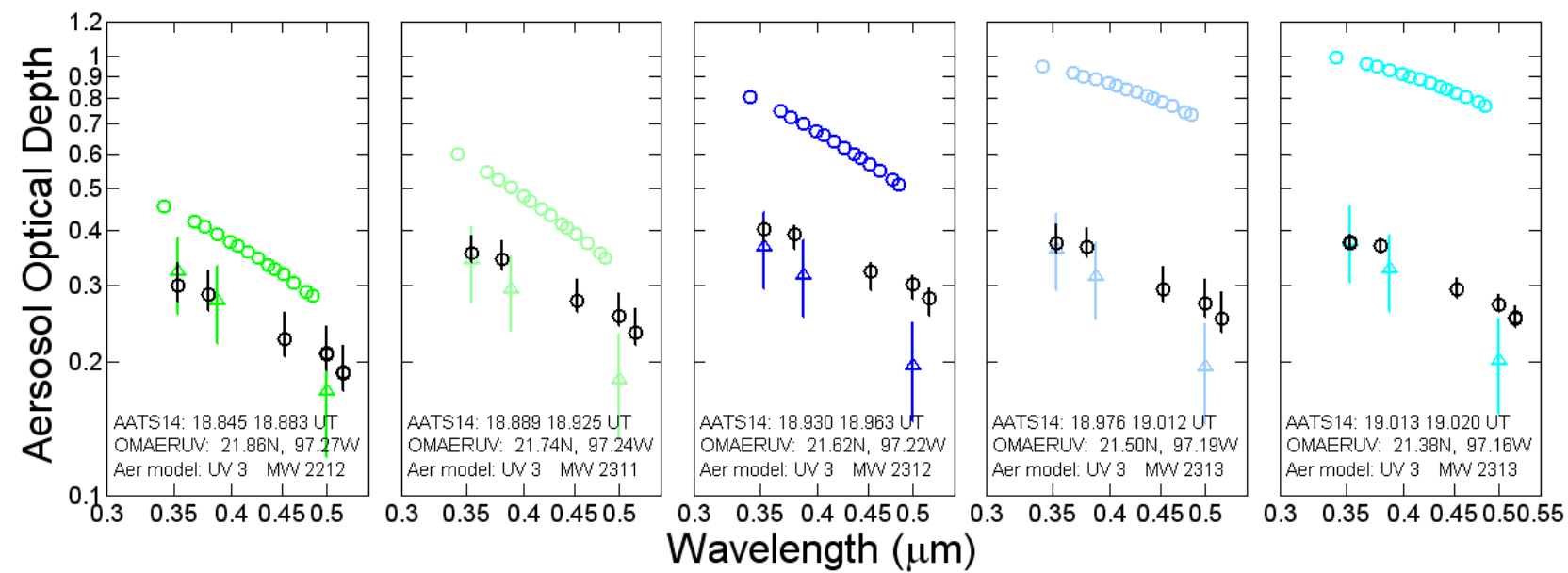

Fig. 8. Comparison of AOD spectra from AATS (black circles with vertical lines showing the range), OMAERO (colored circles), and OMAERUV (triangles with vertical bars giving the expected AOD uncertainty) for the 3 March case study.

However, this exercise may provide some insight into the likelihood of cloud contamination, as the numbers of retrievals passing the threshold were $16,11,1,1$, and 0 from north to south, respectively, which seems consistent with the spatially limited AATS measurements that indicate most of the clouds were in the three southern pixels.

\subsection{March 2006}

The third over-water case study occurred on 17 March, and it is presented in Fig. 9. In Fig. 9a, the J31 flight track is overlaid on the MODIS true color image for the Aqua overpass at 20:04 UT. The corresponding Aura overpass was at 20:19 UT. AATS measurements were acquired during a low altitude (70 ma.s.l.) SW-NE flight leg during a six-minute time period, 19:25-19:31 UT, and temporally near-coincident MODIS and OMI AOD retrievals are available along this short flight segment, as shown in Fig. 9b. Results for the other low-altitude J31 transect ( $\sim 20.9^{\circ}$ to $21.5^{\circ} \mathrm{N}$, flown $20: 57-21: 10 \mathrm{UT}$ ) are not shown because clouds resulted in few AATS and no OMI AOD retrievals. OMAERO retrievals are available for three intersecting pixels, OMAERUV retrievals for two pixels, and MODIS retrievals for four pixels. In fact, MODIS retrievals are available for the entire area shown in Fig. 9b. The MODIS cloud percentages shown in Fig. 9b indicate that the eastern portion of the sampled area was quite cloudcontaminated, which suggests that the OMAERO retrieval in the eastern (dark blue) pixel, at least, is likely cloudcontaminated. Even the MODIS pixels within the two western OMI pixels show some cloud contamination, with the cyan MODIS pixel having a cloud fraction of $40 \%$, which suggests that the OMI retrievals in the OMI pixel encompassing this MODIS pixel are also cloud-contaminated. In fact, OMI retrievals in all three pixels may be cloud-contaminated.
Along the low-altitude segment of the J31 flight track, 19\% of the AATS data points were flagged as cloud-contaminated, and these have been omitted from the AATS AODs presented in Fig. 9c and d.

AATS AOD was not constant along the track, but the variation was only $0.02-0.03$ in the near UV and visible, and even less in the near IR. Most of the AATS measurements fall within the southernmost OMI pixel (cyan) and the remainder lie within the adjacent pixel to the north if only the OMAERUV geolocation data are considered. The AOD spectra retrieved within these two pixels by a single OMI algorithm are essentially equal, but the best-fit OMAERO spectra $\left(\alpha_{\text {OMAERO }}=0.26\right)$ are significantly flatter than and exceed the corresponding OMAERUV spectra $\left(\alpha_{\text {OMAERUV }}=1.82\right)$; corresponding $\alpha_{\text {AATS }}$ values are 1.24 1.26. Both algorithms retrieve a weakly absorbing aerosol in these two pixels. OMAERO AOD magnitudes agree better with the corresponding AATS and MODIS values than do the OMAERUV values, although both appear to agree with AATS within the expected OMI AOD uncertainty (not given for OMAERO). The best-fit OMAERO AOD spectrum retrieved in the eastern pixel (dark blue) is a biomass burning aerosol and significantly exceeds the other retrievals. We discount this retrieval as cloud-contaminated, but it may be no more or less cloud-contaminated than the results for either of the other two pixels. Examination of all OMAERO retrievals (not shown) passing the RMS difference threshold in each pixel yields additional information consistent with the results found in the other two over-water cases, and leads us to conclude that, in terms of the full set of solutions satisfying the OMAERO RMS radiance threshold, there is essentially no difference among the OMAERO retrievals for each of the three pixels for this case. OMAERO retrieved 7-9 solutions that satisfied the RMS threshold in each of the three pixels, despite the appearance of the best-fit OMAERO 

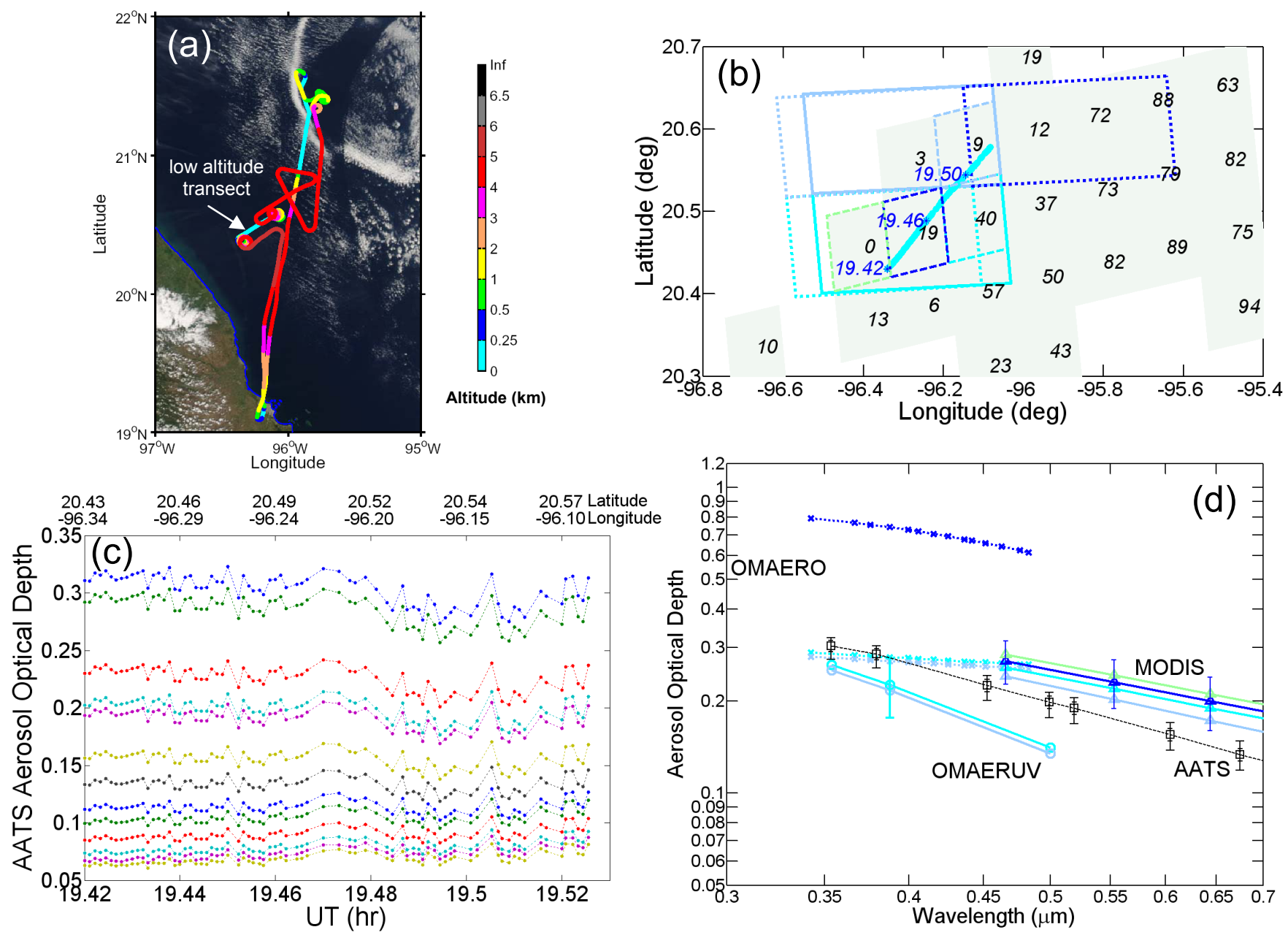

Fig. 9. Case study for 17 March: (a) Aqua-MODIS true color image with color-coded J31 flight track; (b) plan view of the J31 lowaltitude flight track and intersecting OMI (OMAERUV solid, OMAERO dotted) and MODIS (dashed) pixels, with all nonzero MODIS cloud percentages; (c) AOD measured by AATS along the low altitude J31 flight track; (d) AOD spectra retrieved by OMAERO (x symbols with dashed lines), OMAERUV (circles with solid lines), and AATS (squares with short dashed line). The color scheme is the same as in (b).

solutions shown in Fig. 7d; one solution in each corresponds to the weakly absorbing aerosol model 1114 , and the remaining solutions correspond to biomass burning aerosol models. In the cyan and light blue pixels, this weakly absorbing model exhibits (barely) the lowest RMS value; in the dark blue pixel, it has the second lowest RMS value. Because the mean AOD spectra of those solutions satisfying the threshold criterion includes primarily biomass burning aerosol models, each of these mean spectra significantly exceeds the weakly absorbing AOD spectrum and the AATS results and there is little difference among the mean spectra for each of the three pixels.

Figure 10 compares AATS and MODIS AOD spectra for this case. For the four MODIS channels centered at wavelengths below $860 \mathrm{~nm}$, MODIS AODs exceed the corresponding AATS values by $\sim 0.02$ more than the expected MODIS one-sigma uncertainty in the three southern MODIS pixels. RMS and bias differences decrease with wavelength, as shown in Fig. 10.

\subsection{March 2006}

A flight to Mexico City on 19 March presented the only opportunity for comparison of AATS and OMI AODs over land. Figure 11a shows a photo taken at $\sim 19: 25$ UT from the DC8 at an altitude of $7000 \mathrm{~m}$ looking over Mexico City toward the mountain peaks of Ixtaccihuatl and Popocatéptl to the east. The predominant atmospheric feature is the pervasive boundary layer haze over Mexico City. In addition, a small biomass burning plume in the foreground west (right) of the city and large plumes in the mountains to the east can be seen. There are no clouds over the city; the only clouds are over the mountains and beyond. The Aura overpass occurred at 20:07 UT. Figure 11b shows the altitude color-coded J31 

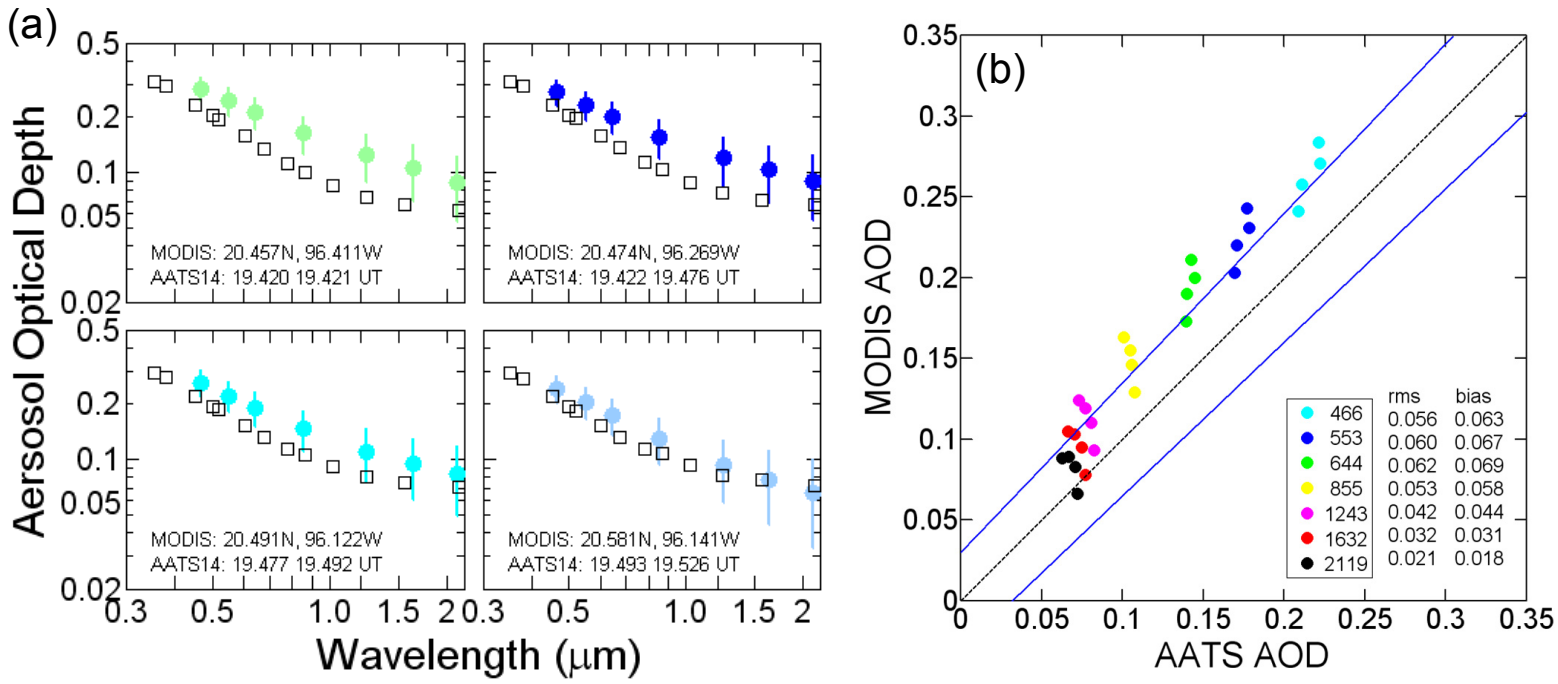

Fig. 10. Case study for 17 March: (a) Comparison of AATS (black squares) and MODIS (colored dots with vertical bars showing estimated uncertainties) AOD spectra within each MODIS pixel; (b) Scatterplot of MODIS vs. AATS AOD, where AATS values have been interpolated to the MODIS wavelengths. The black dashed line gives the one-to-one correspondence, and the two blue lines delineate the expected MODIS AOD uncertainty of $\pm(0.03+0.05 \times$ AOD $)$.

flight track together with intersecting OMI AOD retrieval pixels for the minimum altitude J31 flight segments (dark blue) near the $\mathrm{T} 0$ and $\mathrm{T} 2$ supersites. Here we focus on measurements acquired during these flight segments.

The flight plan called for the $\mathrm{J} 31$ to enter from the ENE, perform a series of profile maneuvers over $\mathrm{T} 2$ in coordination with the DC-8 and under the Aqua and Aura overpasses, then proceed to $\mathrm{T} 0$ for additional coordinated measurements with the DC-8. Unfortunately, extremely low visibility and moderate turbulence within the boundary layer near T2, combined with variable surface terrain below the flight track, prevented the J31 from descending to altitudes below $\sim 420 \mathrm{~m}$ above the local terrain. The visibility near $\mathrm{T} 0$ was markedly improved, but air traffic control restrictions limited the $\mathrm{J} 31$ to a minimum altitudes of $\sim 550 \mathrm{~m}$ above the surface there.

\subsubsection{AATS/OMI measurements near T2}

Figure 12a shows the J31 flight track for the period 19:3519:42 UT, when the aircraft flew in the region between the T2 (2542 ma.s.l.) and T1 (2273 ma.s.l.) sites at altitudes of $\sim 2950 \pm 60 \mathrm{~m}$ a.s.l., which corresponded to $\sim 320$ $800 \mathrm{~m}$ above ground level (a.g.l.). The locations of OMI and MODIS aerosol retrieval pixels spatially coincident with the J31 track are also plotted. The single MODIS pixel near T2 is the only one coincident with the J31 track with an acceptable AOD retrieval quality assurance flag. AATS acquired 101 three-sec average measurements during this flight segment, including 29 data points acquired at altitudes $320-615$ m a.g.l. within the MODIS pixel. As shown in Fig. 12b, the calculated AOD spectra along the T2-T1 track were extremely variable in magnitude, ranging from 0.1 to 0.4 , and they were uncorrelated with aircraft altitude above the local terrain. All spectra exhibited a flat wavelength dependence, with $\alpha_{\text {AATS }}$ of $0.11-0.22$ (c.f. Table 1) for mean spectra calculated at AODs less than $520 \mathrm{~nm}$, indicative of large particles. This flat AOD wavelength dependence was also measured by the AERONET instruments located at $\mathrm{T} 2$ and T1. Mean spectra calculated from AERONET Level 1.0 measurements acquired during the time period 19:27-20:33 UT are plotted in $12 \mathrm{c}$ and yield $\alpha$ of 0.015 at $\mathrm{T} 2$ and 0.025 at $\mathrm{T} 1$. These spectra include six measurements at $\mathrm{T} 2$ and three at $\mathrm{T} 1$; the vertical bars on the data points span the range of AODs measured. We show the AERONET Level 1.0 data because the automated AERONET cloudscreening filter removed cloud-free spectra from the Levels 1.5 and 2.0 data sets due to high AOD variability. The magnitudes of the MODIS AODs fall within the upper limit of the range of AATS AOD spectra but are less than the T2 AERONET mean AOD spectrum, and the MODIS spectrum exhibits a steeper wavelength dependence than the AATS or the AERONET spectra. The mean AATS AOD spectrum (not shown) within the MODIS pixel differs little from the mean spectrum along the entire T2-T1 flight segment.

OMAERO retrieves a biomass-burning aerosol and OMAERUV a dust aerosol. Both yield AOD spectra with steeper wavelength dependence $\left(\alpha_{\text {OMAERUV }}=0.61\right.$, $\left.\alpha_{\text {OMAERO }}=0.76,1.60\right)$ than the AATS or AERONET spectra. OMAERUV AOD magnitudes agree with the AERONET values, but the OMAERO retrievals exceed the corresponding OMAERUV AOD by up to a factor of 4 . Both OMI algorithms retrieve larger AODs within the NE pixel 

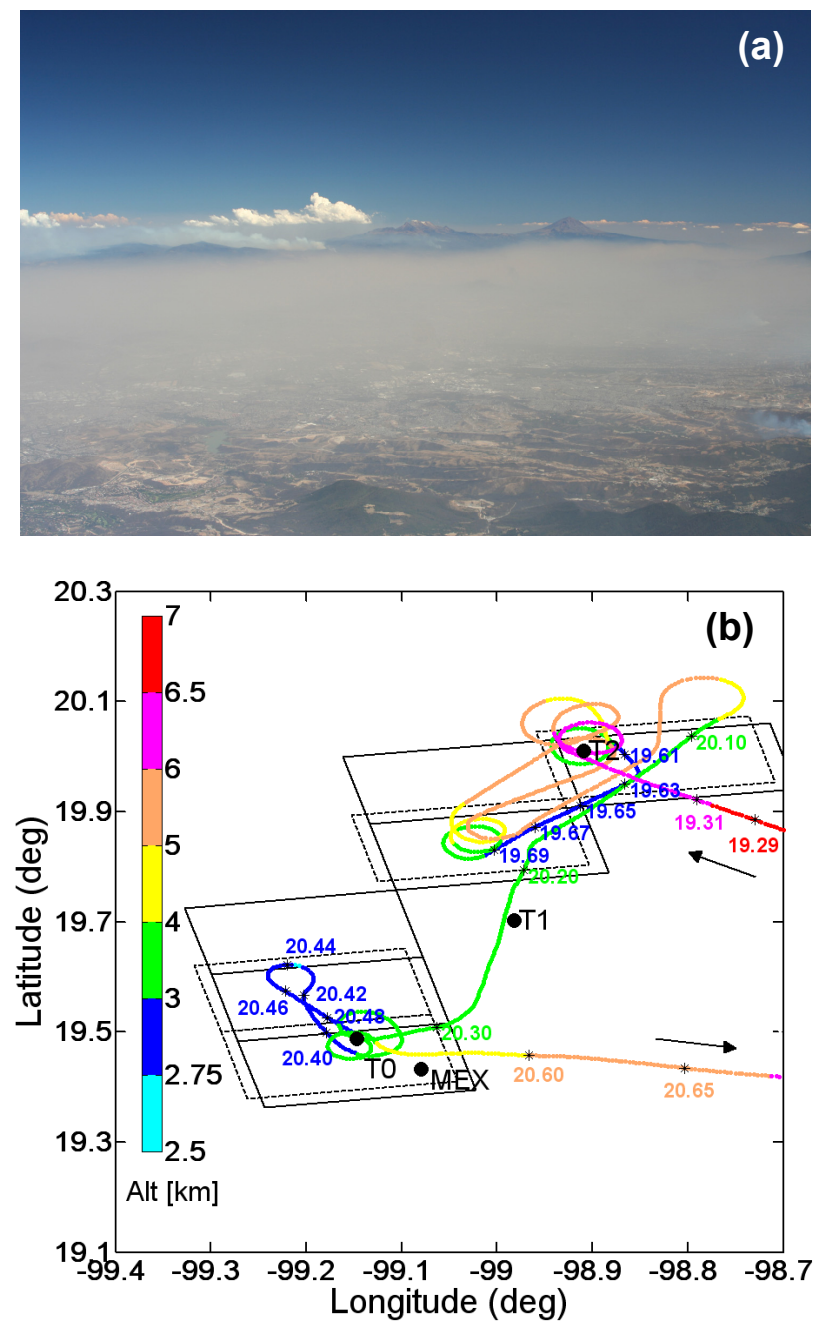

Fig. 11. For the 19 March J31 science flight over the Mexico City urban complex: (a) photo taken looking east from the DC8 at an altitude of $7000 \mathrm{~m}$ at $\sim 19: 25 \mathrm{UT}$; (b) plan view of the altitude color-coded J31 low-altitude flight track and intersecting OMI (OMAERUV solid, OMAERO dotted) pixels. Locations of AERONET sites at T0, T1, and T2 are shown, in addition to the Mexico City International Airport (MEX). The two lowest altitude J31 flight legs near T2 and T0 are dark blue; small black asterisks mark location of J31 corresponding to the listed times in UT.

than those retrieved in the SW pixel. The OMAERUV spectra in the two western pixels are almost equal and are indistinguishable in the plot. There was no OMAERO retrieval corresponding to the OMAERUV NW pixel. AATS AODs are significantly less than the AERONET values, by a minimum of 0.1 even if the maximum values within the range of AATS values given by the vertical bars are considered. However, this is not surprising, as the AATS AODs shown do not include the amount of AOD below the aircraft. The J31 had no sensors to provide coincident in-situ measurements of aerosol scattering and absorption, so we have not attempted to estimate the amount of AOD below the aircraft.
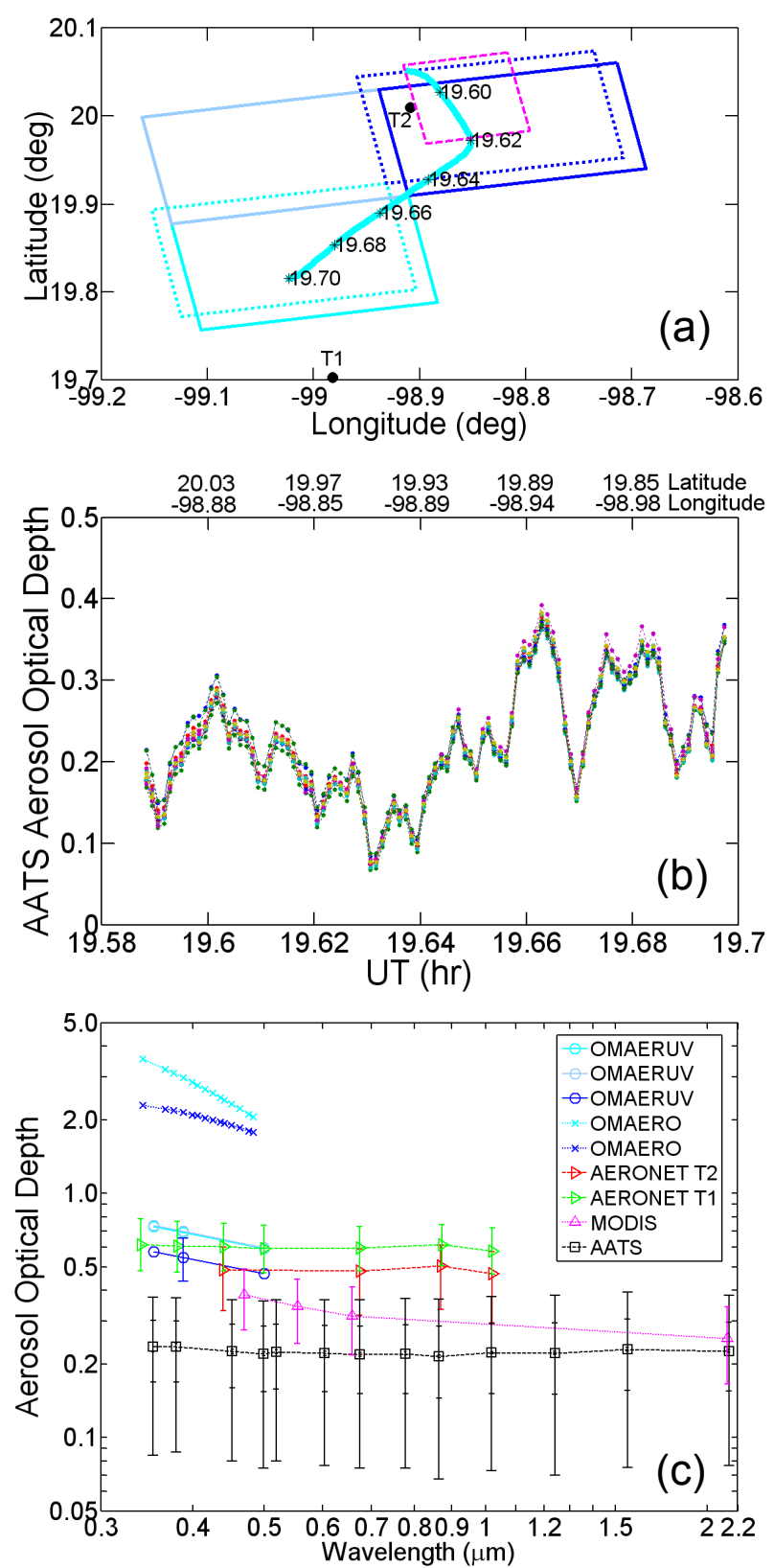

Fig. 12. For the 19 March J31 science flight over the rural area northeast of Mexico City : (a) plan view of the J31 lowest altitude flight track near T2 and intersecting OMI (OMAERUV solid, OMAERO dotted) and MODIS (magenta dashed) pixels, with J31 flight track times in UT; (b) AOD measured by AATS along this flight track (wavelength color code as in Fig. 2) with times corresponding to MODIS pixel boundaries shown by magenta vertical lines; (c) AOD spectra retrieved by OMAERO (x symbols with dotted lines), OMAERUV (circles with solid lines), MODIS (magenta dashed line), AATS (squares with short dashed line), and AERONET (at T1 and T2). As noted in the text, the minimum J31 altitude was $\sim 320 \mathrm{~m}$ a.g.l. 


\subsubsection{AATS/OMI measurements near T0}

Figure 13 presents analogous results for AATS measurements acquired near T0 during the period 20:2420:28 UT. During this time, the J31 flew at altitudes of $\sim 2790 \pm 20 \mathrm{~m}$ a.s.1., or about $600 \mathrm{~m}$ above T0 (2189 $\mathrm{m}$ a.s.1.). The J31 flight track and the OMI retrieval pixels are overlaid in 13a, AATS AODs along the track are plotted in 13b, and the AATS, OMI, and T0 AERONET (Level 1.0) AOD spectra are plotted in 13c. Unlike the AOD spectra measured near T2, those sampled by the sunphotometers near T0 exhibit a distinct decrease with wavelength, with Ångström exponents of $0.58-0.70$ (Table 1) for AATS AOD at wavelengths less than $520 \mathrm{~nm}$. Values of the mean spectrum calculated from three AERONET spectra measured at T0 during the period 20:00-20:33 UT fall within the upper half of the range of AODs measured by AATS. Again, the AATS spectra do not include any estimate of the AOD below the J31, but the AERONET data suggest this contribution is small, and this seems consistent with the flight notes that visibility was much better at $\mathrm{T} 0$ than at T2, as noted in Sect. 3.5 above. The OMAERUV AOD retrievals are approximately twice as large as the AATS values, but with the same wavelength dependence $\left(\alpha_{\text {OMAERUV }}=0.61\right.$ vs. $\alpha_{\text {AATS }}=0.58$ and 0.64$)$. Within the pixel (light blue) that includes the locations of most of the AATS measurements, the OMAERO AODs are about six times the AATS values, but with a similar Ångström exponent $\left(\alpha_{\mathrm{OMAERO}}=0.76\right.$ vs. $\left.\alpha_{\mathrm{AATS}}=0.63\right)$. The OMAERO spectrum in the southern (cyan) pixel has much higher AOD with a steeper wavelength dependence $\left(\alpha_{\text {OMAERO }}=1.60\right.$ vs. $\alpha_{\text {AATS }}=0.11$ ).

\subsubsection{Surface Albedo, SSA, and AAOD at T2 and T0}

The plots in Fig. 14 provide additional analyses of the OMI aerosol retrievals near $\mathrm{T} 2$ and $\mathrm{T} 0$ by examining values of the assumed surface albedo and the retrieved SSA and AAOD. In frames $14 \mathrm{a}$ and $\mathrm{d}$, we compare values of the OMAERO archived Scientific Data Set parameter "terrain reflectivity" with spectral surface albedos derived from SSFR measurements near T2 (12 spectra between 20:28:30 and 20:28:48 UT) and T0 (21 spectra between 19:36:36 and 19:37:05 UT), respectively. The OMAERO "terrain reflectivity" is defined in Kleipool et al. (2008) as a "Lambertian equivalent surface albedo", and is comparable to the SSFRderived surface albedo, which is the "actual" or "blue-sky" surface albedo, as explained in Coddington et al. (2008). At T2, the SSFR surface albedo exceeds the OMAERO assumptions by $<0.01$ at $350 \mathrm{~nm}, \sim 0.01-0.02$ at $388 \mathrm{~nm}$, and $\sim 0.025-0.03$ at $483 \mathrm{~nm}$. The comparison near T0 is similar, except the values of the OMAERO terrain reflectivity within the southern (cyan) pixel, for which the retrieved OMAERO AODs were significantly higher than those in the middle (light blue) pixel, were 0.01-0.02 less than the corresponding values within the light blue pixel.
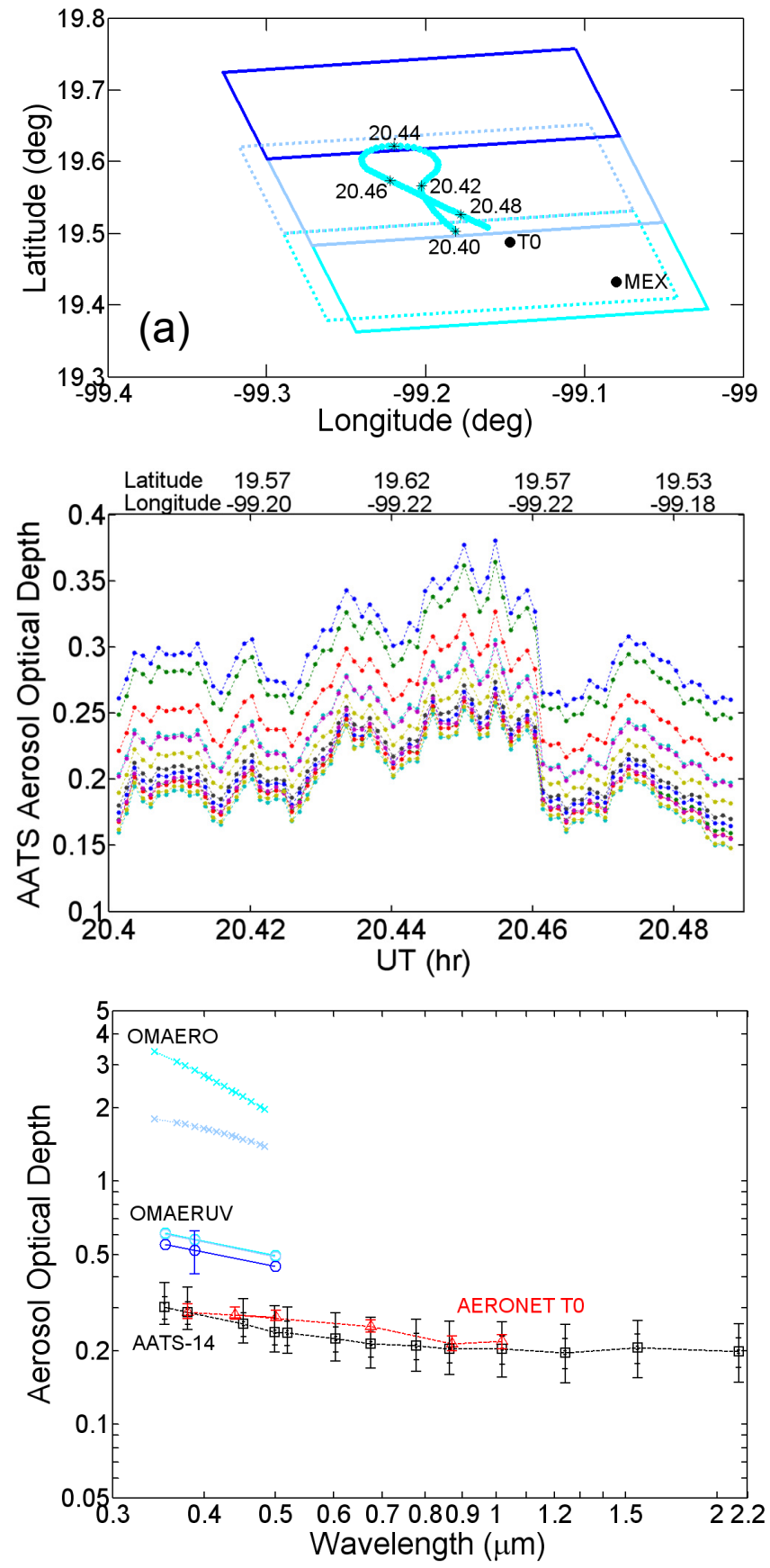

Fig. 13. For the 19 March J31 science flight over the Mexico City urban complex: (a) plan view of the J31 lowest altitude flight track near T0 and intersecting OMI (OMAERUV solid, OMAERO dotted) pixels, with J31 flight track times in UT; (b) AOD measured by AATS along this flight track (wavelength color code as in Fig. 2); (c) AOD spectra retrieved by OMAERO (x symbols with dashed lines), OMAERUV (circles with solid lines), AATS (squares with short dashed line), and AERONET (at T0). The minimum J31 flight altitude was $\sim 590 \mathrm{~m}$ a.g.1. 
$\mathrm{T} 2$
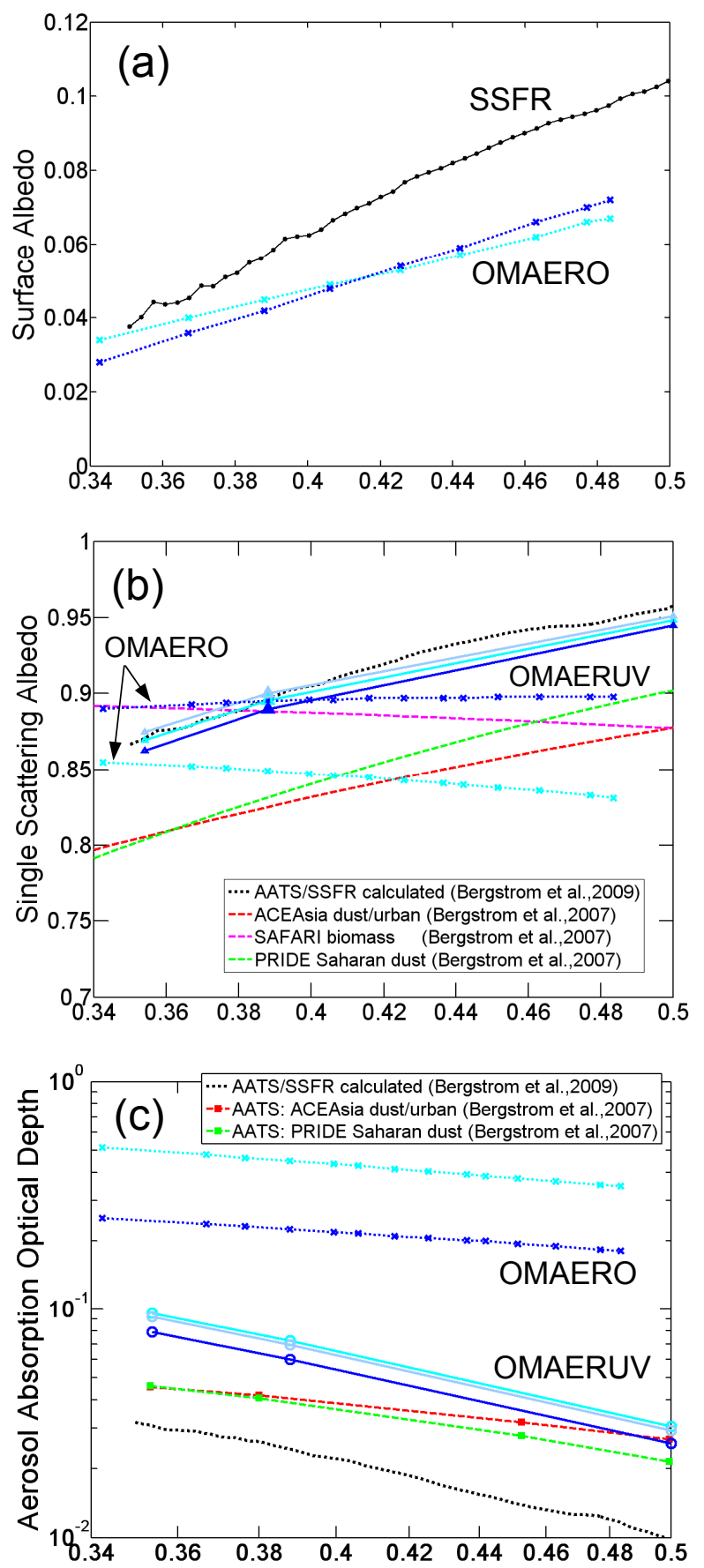

T0
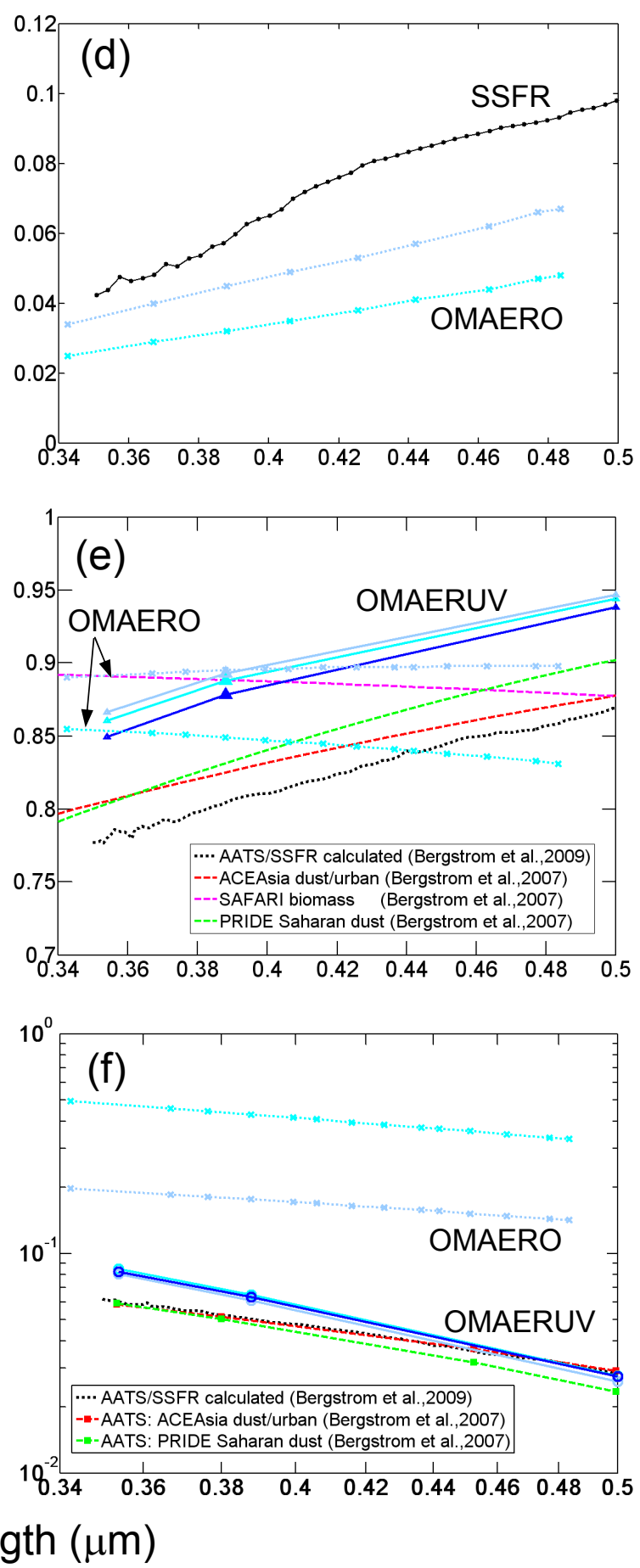

Fig. 14. For AATS and OMI measurements near the T2 (a-c) and T0 (d-f) supersites on 19 March: (a), (d) Terrain reflectivity assumed by the OMAERO retrieval algorithm and surface albedo derived from coincident J31 SSFR measurements; (b), (e) Single scattering albedos from the OMI retrievals, from Bergstrom et al. (2009) for T2 and T0, and from Bergstrom et al. (2007) results for ACE Asia dust/urban, SAFARI biomass-burning, and PRIDE Saharan dust aerosol; (c), (f) AAOD derived from the OMI retrievals, and calculated from AATS AODs assuming various Bergstrom et al. results (see text for discussion). 
Frames $14 \mathrm{~b}$ and e examine the SSA associated with the aerosol models retrieved by the OMI algorithms at $\mathrm{T} 2$ and T0, respectively. Like the AOD, the OMAERUV SSAs are shown at 354 and $500 \mathrm{~nm}$, but these are strictly a function of the retrieved aerosol model, as the primary retrieval is at $388 \mathrm{~nm}$. For the data near T2, the OMAERUV and OMAERO 388-nm SSA in the eastern pixel (dark blue) are equal ( 0.89 , c.f. Table 1$)$, but differ markedly for the SW pixel (cyan). A similar comparison is seen near T0, where the 388-nm SSA values agree to within 0.015 for the pixel (light blue) that includes most of the AATS data, but SSAOMAERO is 0.045 less than the SSA OMAERUV for the southern (cyan) pixel. Obviously, the spectral absorption characteristics of the aerosol models retrieved by the two algorithms differ significantly, as can be seen by the very large difference in SSA slopes at both sites. For comparison, we also plot the SSA calculated (Bergstrom et al., 2009) from AATS and SSFR measurements over T2 and T0 during the J31 flight, in addition to values calculated (Bergstrom et al., 2007) from AATS and SSFR measurements of Saharan dust, Asian dust/urban pollution, and African biomass-burning aerosol during previous field campaigns. The OMAERO retrievals near T2 and T0 correspond to a biomass-burning aerosol model, but the OMAERUV retrievals correspond to a dust model. The magnitudes of the corresponding SSA at $388 \mathrm{~nm}$ agree best with the Bergstrom et al. (2007) biomass-burning SSA, except for the OMAERO cyan pixel. The spectral shapes of the retrieved OMAERO model SSA agree best with the Bergstrom et al. (2007) biomass-burning SSA, but the retrieved OMAERUV model SSA spectral shapes agree best with those of the Bergstrom et al. (2009) Mexico City SSA and the Bergstrom et al. (2007) Saharan dust and Asian dust/urban pollution SSA spectra. No trusted AERONET retrievals of SSA at T0 or T2 are available for comparison near the times of Aura or J31 overpass. At T0, the only trusted SSA retrievals are for AERONET almucantar scans acquired 5-6 $\mathrm{h}$ before (at 13:49, 14:10 and 14:56 UT) and 2-3 h after (at 22:37, 23:22 and 23:43 UT) the Aura overpass time, but the AERONET direct sun measurements indicate that the particles were much larger while the J31 was there than they were during these times.

Frames $14 \mathrm{c}$ and $\mathrm{f}$ plot the OMI retrievals of AAOD for the T2 and T0 measurements, respectively. For comparison, we also show AAOD estimated from the AATS AOD values (uncorrected for AOD below the J31) by assuming various Bergstrom et al. SSA spectra. At each site, the OMAERO AAOD values significantly exceed the OMAERUV values, but the magnitude of the differences cannot be explained by the difference in SSAs. Also, at each site the OMAERUV AAOD values are much closer to the AATS AAOD estimates (using the Bergstrom et al. Mexico City, Saharan dust, or Asian dust/urban pollution SSA) than are the OMAERO values.

\section{Discussion and conclusions}

We have compared AOD retrievals from spatially and temporally near-coincident measurements acquired by AATS and by OMI for three cases over the Gulf of Mexico and one over Mexico City. Aqua-MODIS AOD retrievals are available for two of the three over-water comparisons -10 and 17 March, and these have been shown to agree with AATS AODs to within MODIS AOD retrieval uncertainties for 10 March and to within MODIS uncertainties plus 0.02 for 17 March. Results have been presented separately for two segments of the J31 flight to Mexico City on 19 March the first over the non-urban T2 supersite northeast of the city and the second over the T0 supersite near the center of the city. A MODIS AOD retrieval within a single pixel including the T2 site and AOD spectra derived from near-coincident AERONET measurements at the T0, T1, and T2 sites have been included in the analyses.

The three over-water AATS/OMI comparisons are of special interest because of the scarcity of surface-based measurements available for validation of OMI aerosol retrievals over water (Torres et al., 2007). The 10 March coincident event represents an excellent test of the OMAERUV and OMAERO retrieval algorithms for a variety of reasons. First, the J31 flight track included a 20-min low altitude $(60 \mathrm{~m}$ a.s.l.) transect that intersected eight OMAERUV and seven OMAERO pixels and, based on the MODIS MOD04L2 cloud fraction product, at least four of these pixels were cloud-free. This is important because subpixel cloud contamination within the nominal $13 \times 24 \mathrm{~km}^{2}$ OMI pixel is one of the largest sources of uncertainty in the retrieval of AOD from OMI measurements (Torres et al., 2007; Ahn et al., 2008; Curier et al., 2008). Secondly, AATS measured moderate AODs $(0.21-0.40)$ at wavelengths within the OMI AOD retrieval spectral range. Finally, AATS observed a small but distinct AOD gradient $(\sim 0.05)$ over that portion of the aircraft track that coincided with the cloud-free OMI pixels.

For the 10 March comparison, if the OMAERUV retrieval with the largest AODs is omitted due to likely cloudcontamination in that pixel, then all OMAERUV retrievals in the remaining seven pixels significantly underestimate (by $\sim 0.14-0.20$ at OMI $388 \mathrm{~nm} /$ AATS $380 \mathrm{~nm}$ ) the corresponding AATS (and MODIS) AODs, and all OMAERO best-fit retrievals significantly exceed (by $\sim 0.30-0.50$ at $388 / 380 \mathrm{~nm}$ ) the AATS values. Both OMI algorithms retrieve an AOD gradient corresponding to that measured by AATS, although the magnitudes of the gradient differ slightly. All OMAERUV retrievals correspond to a nonabsorbing sulfate aerosol with a refractive index of 1.40-0i, whereas all OMAERO best-fit retrievals correspond to a biomass-burning aerosol with a refractive index of 1.5-0.03i $(\mathrm{SSA} \approx 0.85)$. For both OMAERUV and OMAERO, corresponding Ångström exponents are within 0.2 of the AATS values. 
When the OMAERO retrieval was rerun restricting the set of allowable aerosol models to weakly absorbing aerosols, the retrieved AOD spectra were found to agree much more closely in magnitude with the AATS results but exhibit a much flatter spectral behavior. Interestingly, the aerosol model (model 1114, with a refractive index of 1.40-5.0e-08i) corresponding to the best-fit solution is the same in each of the seven OMAERO pixels and is also among those solutions that passed the residual reflectance RMS threshold test for the archived data product in five of the seven, including the four cloud-free, pixels. These results indicate that the information in the OMI spectra in this case is not enough to select the correct aerosol main type and the algorithm should be constrained further to yield reliable AODs for such cases. Analysis of the RMS radiance error of the fit shows very little difference among the acceptable solutions. If mean values calculated over the solutions passing the RMS threshold are used instead of the best-fit AOD spectra, the agreement between the OMAERO AOD retrievals and the AATS measurements improves.

The strength of the near-UV technique is its ability to measure aerosol absorption and, as noted in Sect. 2.1, the AOD product is considered much less reliable than AAOD (Torres et al., 2007). Preliminary results from Bergstrom et al. (2009) indicate that the overwater aerosol was considerably less absorbing than the Mexico City aerosol. If the aerosol was either non-absorbing, as the OMAERUV retrievals suggest, or even weakly absorbing, then it is not too surprising that the OMAERUV algorithm does not have the sensitivity (within the set of available aerosol models and forward-calculated TOA reflectances) to retrieve the correct magnitude of the AOD for this case. Although it is beyond the scope of this study, it would be interesting to understand what incremental changes in the measured reflectances at $354 \mathrm{~nm}$ and $388 \mathrm{~nm}$ would have been required to cause the algorithm to retrieve a weakly absorbing instead of a nonabsorbing aerosol and, hence, larger AODs.

The over-water AATS/OMI coincidences on 3 and 17 March are less optimal for evaluating the performance of the OMI aerosol retrieval algorithms due primarily to a higher likelihood of sub-pixel cloud contamination but also due to fewer AATS AOD measurements intersecting fewer OMI pixels than for the 10 March comparison. Even so, both comparisons are useful. The AOD magnitudes measured by AATS during these events were comparable to those measured on 10 March.

On 3 March, there were coincident AATS measurements within five OMI pixels, but the AATS measurements were acquired about one hour before the OMI overpass. Due to sun glint there are no corresponding MODIS AOD retrievals and, hence, no MODIS cloud fractions for this event. Based on the number of AATS data points removed by the standard AATS cloud-screening procedure, it appears that only the northernmost OMI pixel may have been cloud-free. AATS measured a larger AOD gradient $(\sim 0.10$ at OMI wavelengths) on 3 March than on 10 March, and again both OMI algorithms retrieve the sign, although not the magnitude, of this gradient. AATS and OMAERUV observe this gradient only within the three northernmost pixels, but OMAERO retrievals continue the gradient across all pixels. As is the case for 10 March, OMAERUV retrieves a non-absorbing aerosol and OMAERO (best-fit retrieval) a biomass-burning aerosol model. We showed in Fig. 8 that in all five pixels the OMAERUV AOD at $388 \mathrm{~nm}$ agrees with the AATS AOD to within the estimated uncertainty. The OMAERO best-fit AOD spectrum significantly exceeds the AATS AOD spectrum in all pixels, and the difference increases along the J31 track to the south, where sub-pixel cloud contamination may have been greater. Similar to the 10 March case, the algorithm chooses the wrong aerosol model, showing that stronger constraints on the aerosol main type should be used for this case.

On 17 March, the J31 low altitude track intersected only two OMAERUV and three OMAERO retrieval pixels, and most of the AATS data points fall within a single pixel. The OMAERO best-fit AOD spectrum significantly exceeds the AATS spectrum for the one pixel for which there is no corresponding OMAERUV retrieval, but this retrieval is judged to be cloud-contaminated based on MODIS cloud fractions and it is also the only best-fit OMAERO solution that corresponds to a biomass-burning aerosol. For the other two pixels, OMAERO retrieves a best-fit weakly absorbing aerosol model and OMAERUV a non-absorbing aerosol. Both OMI algorithms retrieve AODs at $388 \mathrm{~nm}$ that agree with the AATS values to within expected uncertainties, although the OMAERUV values appear to be biased slightly low. Consistent with the results found in the March 3 and March 10 cases, the OMAERO AOD spectrum corresponding to a weakly absorbing aerosol model is significantly flatter than the mean AATS spectrum. Examination of all OMAERO solutions that passed the RMS difference threshold for each of the three pixels reveals that one of several solutions in each pixel corresponds to the weakly absorbing aerosol model 1114 and there is little difference among the OMAERO mean AOD spectra for each of the pixels. MODIS cloud fractions suggest that, in fact, OMI retrievals in all three pixels may be cloud-contaminated.

During the J31 flight to Mexico City on 19 March, AATS measured AOD spectra near T2 and just north of T1 that were extremely variable in magnitude, but all exhibit a flat spectral dependence indicative of large dust particles. AOD spectra derived from AERONET measurements taken at $\mathrm{T} 1$ and T2 also show a flat wavelength dependence, but because the J31 was unable to fly lower than $\sim 320 \mathrm{~m}$ above the underlying terrain due to poor visibility and moderate turbulence, the resultant AATS AODs not adjusted for the AOD below the aircraft are $\sim 30-80 \%$ lower than the AERONET values. OMAERUV AODs agree well with the AERONET data, although the OMAERUV spectra exhibit a steeper wavelength dependence. The MODIS AOD retrieval in the pixel 
including T2 exhibits magnitudes between the AATS and AERONET values and a steeper wavelength dependence. Corresponding OMAERO AODs exceed the OMAERUV and AERONET values by factors of $\sim 3-8$. The best fit OMAERO solutions correspond to biomass-burning aerosol models, whereas the OMAERUV retrievals yield a dust aerosol model. At T0, the visibility from the J31 was markedly better than that at T2, and AATS AOD spectra measured at 550-750 $\mathrm{m}$ a.g.l. were much less variable and exhibit a distinct decrease with wavelength, with $\alpha_{\text {AATS }} \approx 0.6$. AATS and AERONET spectra at T0 agree well within respective uncertainties, despite no adjustment to the AATS values for the AOD below the aircraft, and this suggests that the magnitude of this AOD contribution was small. OMAERUV retrievals are about twice as large as the AATS values, but with a similar wavelength dependence. Corresponding OMAERO retrievals are 7 to 10 times larger than the AATS AODs.

One source of the large differences between the OMAERO and AATS/AERONET AODs at both T2 and T0 may be the retrieved aerosol model type (biomass-burning aerosol). However, the most significant source of the observed discrepancies may be an incorrect assumption for the surface albedo spectrum. We have calculated surface albedo spectra at T2 and $\mathrm{T} 0$ from coincident measurements from the $\mathrm{J} 31$ by the SSFR, and these exceed the terrain reflectivity spectra used in the OMAERO retrievals by $<0.01$ at $350 \mathrm{~nm}$ to $0.025-0.03$ at $483 \mathrm{~nm}$. We have not attempted to quantify the sensitivity of these OMAERO AOD retrievals to the assumed value of terrain reflectivity. However, it is well recognized that the surface albedo assumption can and does affect satellite retrievals of AOD (e.g. Veefkind et al., 1998; Torres et al., 2002, 2007; Currier et al., 2008; Veihelmann et al., 2007). In a related study, Castanho et al. (2007) have used ground-based sunphotometer data acquired in and near Mexico City before and during MILAGRO to investigate the effect of an incorrect assumption of the visible/near-infrared surface reflectance ratio on retrieval of AOD from coincident MODIS measurements. They find significant improvement in the agreement between the sunphotometer and MODIS AODs after use of a larger surface reflectance ratio for the urban Mexico City area than that typically assumed in the MODIS operational algorithm. Separately, Barnard et al. (2008) report enhanced absorption in the near-UV spectral range ( 250 to $400 \mathrm{~nm}$ ) due to absorption by organic carbon in the Mexico City area. If the aerosol models used in the forward radiative transfer calculations of TOA reflectance for the OMAERO retrievals underestimate the amount of absorption in the near-UV, then this could be another source of uncertainty in the retrieved AAOD and AOD.

In summary, we have found that OMAERO AOD retrievals exceed AATS and MODIS values in two of three over-water comparisons, and OMAERO retrievals exceed AATS and AERONET values at a non-urban site and an urban site for a single Aura overpass of the Mexico City area. These results are consistent with the findings of
Curier et al. (2008), who report differences of the same order of magnitude as those we report here and who conclude that OMAERO AODs tend to overestimate MODIS and AERONET values. The corresponding OMAERUV retrievals slightly underestimate the AATS values for the cloud-free pixels of the 10 March over-water case, and agree with AATS values to within uncertainties for the other two over-water cases. For the Mexico City case, the OMAERUV retrievals are consistent with AERONET values at T2/T1, but exceed the AATS and AERONET values in the center of the city near T0.

The current study has been limited in scope by the availability of coincident data, but that should not diminish the significance of the findings. It points to the need for additional OMI aerosol validation attempts using ground-based and airborne correlative sensors over the ocean, at least, and the need for additional in-depth OMI aerosol retrieval sensitivity studies such as that of Veihelmann et al. (2007) to explain the observed AOD discrepancies over land and over ocean.

Acknowledgements. The MILAGRO/INTEX-B Campaign is a collaborative effort of a large number of participants with the support of multi-national agencies. The MILAGRO/INTEX-B participants would like to thank the governments of the Federal District, the States of Mexico, Hidalgo and Veracruz, the Mexican Ministries of the Environment, Foreign Relations, Defense and Finance for their logistical support; IMP, U-Tecámac, and Rancho La Bisnega for hosting the supersites as well as many other Mexican institutions for their support. The photograph in Fig. 11a was taken and provided to us by Cameron McNaughton of the University of Hawaii School of Ocean and Earth Science Technology. We thank all INTEX-B/MILAGRO participants and sponsoring agencies for making this research possible. J31 measurements were supported by the NASA Radiation Science Program.

Edited by: S. Madronich

\section{References}

Ahn, C., Torres, O., and Bhartia, P. K.: Comparison of ozone monitoring instrument UV aerosol products with Aqua/Moderate Resolution Imaging Spectroradiometer and Multiangle Imaging Spectroradiometer observations in 2006, J. Geophys. Res., 113, D16S27, doi:10.1029/2007JD008832, 2008.

Barnard, J. C., Volkamer, R., and Kassianov, E. I.: Estimation of the mass absorption cross section of the organic carbon component of aerosols in the Mexico City Metropolitan Area, Atmos. Chem. Phys., 8, 6665-6679, 2008,

http://www.atmos-chem-phys.net/8/6665/2008/.

Bergstrom, R. W., Pilewskie, P., Russell, P. B., Redemann, J., Bond, T. C., Quinn, P. K., and Sierau, B.: Spectral absorption properties of atmospheric aerosols, Atmos. Chem. Phys., 7, 5937-5943, 2007,

http://www.atmos-chem-phys.net/7/5937/2007/.

Bergstrom, R. W., Schmidt, K. S., Coddington, O., Pilewskie, P., Livingston, J., Redemann, J., and Russell, P.: Aerosol absorp- 
tion in the Mexico City area; results from airborne measurements during MILAGRO/INTEX-B, manuscript in preparation for submission to Atmos. Chem. Phys. Discuss., 2009.

Brinksma, E. J., Pinardi, G., Volten, H., Braak, R., Richter, A., Schönhardt, A., van Roozendael, M., Fayt, C., Hermans, C., Dirksen, R. J., Vlemmix, T., Berkhout, A. J. C., Swart, D. P. J., Oertjen, H., Wittrock, F., Wagner, T., Ibrahim, O. W., de Leeuw, G., Moerman, M., Curier, R. L., Celarier, E. A., Cede, A., Knap, W. H., Veefkind, J. P., Eskes, H. J., Allaart, M., Rothe, R., Piters, A. J. M., and Levelt, P. F.: The 2005 and 2006 DANDELIONS NO2 and aerosol intercomparison campaigns, J. Geophys. Res., 113, D16S46, doi:10.1029/2007JD008808, 2008.

de Almeida Castanho, A. D., Prinn, R., Martins, V., Herold, M., Ichoku, C., and Molina, L. T.: Analysis of Visible/SWIR surface reflectance ratios for aerosol retrievals from satellite in Mexico City urban area, Atmos. Chem. Phys., 7, 5467-5477, 2007, http://www.atmos-chem-phys.net/7/5467/2007/.

Coddington, O., Schmidt, K. S., Pilewskie, P., Gore, W. J., Bergstrom, R. W., Román, M., Redemann, J., Russell, P. B., Liu, J., and Schaaf, C. C.: Aircraft measurements of spectral surface albedo and its consistency with ground-based and space-borne observations, J. Geophys. Res., 113, D17209, doi:10.1029/2008JD010089, 2008.

Curier, R. L., Veefkind, J. P., Braak, R., Veihelmann, B., Torres, O., and de Leeuw, G.: Retrieval of aerosol optical properties from OMI radiances using a multiwavelength algorithm: Application to western Europe, J. Geophys. Res., 113, D17S90, doi:10.1029/2007JD008738, 2008.

Dubovik, O., Smirnov, A., Holben, B. N., King, M. D., Kaufman, Y. J., Eck, T. F., and Slutsker, I.: Accuracy assessments of aerosol optical properties retrieved from Aerosol Robotic Network (AERONET) Sun and sky radiance measurements, J. Geophys. Res., 105(D8), 9791-9806, 2000.

Dubovik, O., Holben, B. N., Eck, T. F., Smirnov, A., Kaufman, Y. J., King, M. D., Tanré, D., and Slutsker, I.: Variabilityof absorption and optical properties of key aerosol types observed in worldwide locations, J. Atmos. Sci., 59, 590-608, 2002.

Eck, T. F., Holben, B. N., Dubovik, O., Smirnov, A., Slutsker, I., Lobert, M., and Ramanathan, V.: Column-integrated aerosol optical properties over the Maldives during the northeast monsoon for 1998-2000, J. Geophys. Res., 106, 28555-28566, 2001.

Herman, J. R., Bhartia, P. K., Torres, O., Hsu, C., Seftor, C., and Celarier, E.: Global distribution of UV-absorbing aerosol from Nimbus-7/TOMS data, J. Geophys. Res., 102, 16911-16922, 1997.

Holben, B. N., Eck, T. F., Slutsker, I., Tanré, D., Buis, J. P., Setzer, A., Vermote, E., Reagan, J. A., Kaufman, Y. J., Nakajima, F., Lavenu, T., Jankowiak, I., and Smirnov, A.: AERONET - A federated instrument network and data archive for aereosol characterization, Remote Sens. Environ., 66, 1-16, 1998.

Holben, B. N., Tanré, D., Smirnov, A., Eck, T. F., Slutsker, I., Abuhassan, N., Newcomb, W. W., Schafer, J. S., Chatenet, B., Lavenu, F., Kaufman, Y. J., Vande Castle, J., Setzer, A., Markham, B., Clark, D., Frouin, R., Halthore, R., Karneli, A., O’Neill, N. T., Pietras, C., Pinker, R. T., Voss, K., and Zibordi, G.: An emerging ground-based aerosol climatology: Aerosol optical depth from AERONET, J. Geophys. Res., 106(D11), 12067-12097, 2001.

King, M. D., Kaufman, Y. J., Menzel, W. P., and Tanré, D.: Remote- sensing of cloud, aerosol, and water-vapor properties form the Moderate Resolution Imaging Spectrometer (MODIS), IEEE T. Geosci. Remote, 30(1), 2-27, 1992.

Kleipool, Q. L., Dobber, M. R., de Haan, J. F., and Levelt, P. F: Earth surface reflectance climatology from 3 years of OMI data, J. Geophys. Res., 113, D18308, doi:10.1029/2008JD010290, 2008.

Levelt, P. F., Hilsenrath, E., Leppelmeier, G. W., van den Ooord, G. H. J., Bhartia, P. K., Taminnen, J., de Haan, J. F., and Veefkind, J. P.: Science objectives of the Ozone Monitoring Instrument, IEEE T. Geosci. Remote, 44(5), 1283-1287, 2006.

Levy, R. C., Remer, L. A., Mattoo, S., Vermote, E. F., and Kaufman, Y. J.: Second-generation operational algorithm: Retrieval of aerosol properties over land from inversion of Moderate Resolution Imaging Spectroradiometer spectral reflectance, J. Geophys. Res., 112, D13211, doi:10.1029/2006JD007811, 2007.

Li, R.-R., Kaufman, Y. J., Gao, B.-C., and Davis, C. O.: Remote sensing of suspended sediments and shallow coastal waters, IEEE T. Geosci. Remote, 41, 559-566, 2003.

Livingston, J. M., Schmid, B., Russell, P. B., Eilers, J. A., Kolyer, R. W., Redemann, J., Ramirez, S. R., Yee, J.-H., Swartz, W. H., Trepte, C. R., Thomason, L. W., Pitts, M. C., Avery, M. A., Randall, C. E., Lumpe, J. D., Bevilacqua, R. M., Bittner, M., Erbertseder, T., McPeters, R. D., Shetter, R. E., Browell, E. V., Kerr, J. B., and Lamb, K.: Retrieval of ozone column content from airborne Sun photometer measurements during SOLVE II: comparison with coincident satellite and aircraft measurements, Atmos. Chem. Phys., 5, 2035-2054, 2005,

http://www.atmos-chem-phys.net/5/2035/2005/.

Livingston, J. M., Schmid, B., Redemann, J., Russell, P. B., Ramirez, S. A., Eilers, J., Gore, W., Howard, S., Pommier, J., Fetzer, E. J., Seemann, S. W., Borbas, E., Wolfe, D. E., and Thompson, A. M.: Comparison of water vapor measurements by airborne Sun photometer and near-coincident in situ and satellite sensors during INTEX/ITCT 2004, J. Geophys. Res., 112, D12S16, doi:10.1029/2006JD007733, 2007.

Martins, J. V., Tanré, D., Remer, L., Kaufman, Y., Mattoo, S., and Levy, R.: MODIS cloud screening for remote sensing of aerosols over oceans using spatial variability, Geophys. Res. Lett., 29(12), 8009, doi:10.1029/2001GL013252, 2002.

Michalsky, J. J., Liljegren, J. C., and Harrison, L. C.: A comparison of Sun photometer derivations of total column water vapor and ozone to standard measures of same at the Southern Great Plains Atmospheric Radiation site, J. Geophys. Res., 100, 25995-26003, 1995.

Molina, L. T., Madronich, S., Gaffney, J., et al.: An Overview of MILAGRO 2006 Campaign: Mexico City Emissions and its Transport and Transformation, manuscript submitted to Atmos. Chem. Phys. Discuss., 2009.

Pilewskie, P., Pommier, J., Bergstrom, R., Gore, W., Howard, S., Rabbette, M., Schmid, B., Hobbs, P. V., and Tsay, S. C.: Solar spectral radiative forcing during the Southern African Regional Science Initiative, J. Geophys. Res., 108(D13), 8486, doi:10.1029/2002JD002411, 2003.

Reagan, J., Thome, K., Herman, B., Stone, R., Deluisi, J., and Snider, J.: A comparison of columnar water-vapor retrievals obtained with near-IR solar radiometer and microwave radiometer measurements, J. Appl. Meteorol., 34, 1384-1391, 1995.

Redemann, J., Zhang, Q., Livingston, J., Russell, P., Shinozuka, Y., 
Clarke, A., Johnson, R., and Levy, R.: Testing aerosol properties in MODIS (MOD04/MYD04) Collection 4 and 5 using airborne sunphotometer observations in INTEX-B/MILAGRO, Atmos. Chem. Phys. Discuss., 9, 11753-11781, 2009,

http://www.atmos-chem-phys-discuss.net/9/11753/2009/.

Remer, L., Kaufman, Y. J., Tanré, D., Mattoo, S., Chu, D. A., Martins, J. V., Li, R.-R., Ichoku, C., Levy, R. C., Kleidman, R. G., Eck, T. F., Vermote, E., and Holben, B. N.: The MODIS aerosol algorithm, products and validation, J. Atmos. Sci., 62, 947-973, 2005.

Russell, P. B., Livingston, J. M., Dutton, E. G., Pueschel, R. F., Reagan, J. A., DeFoor, T. E., Box, M. A., Allen, D., Pilewskie, P., Herman, B. M., Kinne, S. A., and Hofmann, D. J.: Pinatubo and pre-Pinatubo optical-depth spectra: Mauna Loa measurements, comparisons, inferred particle size distributions, radiative effects, and relationship to lidar data, J. Geophys. Res., 98, 22969-22985, 1993a.

Russell, P. B., Livingston, J. M., Pueschel, R. F., Reagan, J. A., Browell, E. V., Toon, G. C., Newman, P. A., Schoeberl, M. R., Lait, L. R., Pfister, L., Gao, Q., and Herman, B. M.: PostPinatubo optical depth spectra vs. latitude and vortex structure: Airborne tracking sunphotometer measurements in AASE II, Geophys. Res. Lett., 20, 2571-2574, 1993b.

Russell, P., Livingston, J., Schmid, B., Eilers, J., Kolyer, R., Redemann, J., Ramirez, S., Yee, J.-H., Swartz, W., Shetter, R., Trepte, C., Risley Jr., A., Wenny, B., Zawodny, J., Chu, W., Pitts, M., Lumpe, J., Fromm, M., Randall, C., Hoppel, K., and Bevilacqua, R.: Aerosol optical depth measurements by airborne sun photometer in SOLVE II: Comparisons to SAGE III, POAM III and airborne spectrometer measurements, Atmos. Chem. Phys., 5, 1311-1339, 2005, http://www.atmos-chem-phys.net/5/1311/2005/.

Russell, P. B., Livingston, J. M., Redemann, J., Schmid, B., Ramirez, S. A., Eilers, J., Kahn, R., Chu, A., Remer, L., Quinn, P. K., Rood, M. J., and Wang, W.: Multi-gridcell validation of satellite aerosol property retrievals in INTEX/ITCT/ICARTT 2004, J. Geophys. Res., 112, D12S09, doi:10.1029/2006JD007606, 2007.

Schmid, B. and Wehrli, C.: Comparison of sun photometer calibration by Langley technique and standard lamp, Appl. Optics, 34, 4500-4512, 1995.

Schmid, B., Thome, K. J., Demoulin, P., Peter, R., Matzler, C., and Sekler, J.: Comparison of modeled and empirical approaches for retrieving columnar water vapor from solar transmittance measurements in the $0.94-\mu \mathrm{m}$ region, J. Geophys. Res., 101, 93459358, 1996.

Schmid, B., Spyak, P. R., Biggar, S. F., Wehrli, C., Sekler, J., Ingold, T., Mätzler, C., and Kämpfer, N.: Evaluation of the applicability of solar and lamp radiometric calibrations of a precision Sun photometer operating between 300 and $1025 \mathrm{~nm}$, Appl. Optics, 37, 3923-3941, 1998.
Schmid, B., Michalsky, J. J., Slater, D. W., Barnard, J. C., Halthore, R. N., Liljegren, J. C., Holben, B. N., Eck, T. F., Livingston, J. M., Russell, P. B., Ingold, T., and Slutsker, I.: Comparison of columnar water-vapor measurements from solar transmittance methods, Appl. Optics, 40, 1886-1896, 2001.

Schmid, B., Redemann, J., Russell, P. B., Hobbs, P. V., Hlavka, D. L., McGill, M. J., Holben, B. N., Welton, E. J., Campbell, J. R., Torres, O., Kahn, R. A., Diner, D. J., Helmlinger, M. C., Chu, D. A., Robles-Gonzalez, C., and de Leeuw, G.: Coordinated airborne, spaceborne, and ground-based measurements of massive, thick aerosol layers during the dry season in Southern Africa, J. Geophys. Res., 108(D13), 8496, doi:10.1029/2002JD002297, 2003a.

Schmid, B., Hegg, D. A., Wang, J., Bates, D., Redemann, J., Russell, P. B., Livingston, J. M., Jonsson, H. H., Welton, E. J., Seinfeld, J. H., Flagan, R. C., Covert, D. S., Dubovik, O., Jefferson, A.: Column closure studies of lower tropospheric aerosol and water vapor during ACE-Asia using airborne sunphotometer, airborne in-situ and ship-based lidar measurements, J. Geophys. Res. , 108(D23), 8656, doi:10.10292002JD003361, 2003b.

Smirnov, A., Holben, B. N., Eck, T. F., Dubovik, O., and Slutsker, I.: Cloud screening and quality control algorithms for the AERONET data base, Remote Sens. Enviorn., 73(3), 337-349, 2000.

Torres, O., Bhartia, P. K., Herman, J. R., and Ahmad, Z.: Derivation of aerosol properties from satellite measurements of backscattered ultraviolet radiation: Theoretical basis, J. Geophys. Res., 103, 17099-17110, 1998.

Torres, O., Decae, R., Veefkind, J. P., and de Leeuw, G.: OMI aerosol retrieval algorithm, in OMI Algorithm Theoretical Basis Document: Clouds, Aerosols, and Surface UV Irradiance, edited by Stammes, P., NASA Goddard Space Flight Cent., Greenbelt, Md. OMI-ATBD-03, vol. 3, version 2, pp. 47-71, 2002. (Available at http://eospso.gsfc.nasa.gov/eos_homepage/for-scientists/ atbd/docs/OMI/ATBD-OMI-03.pdf)

Torres, O., Tanskanen, A., Veihelmann, B., Ahn, C., Braak, R., Bhartia, P. K., Veefkind, P., and Levelt, P.: Aerosols and surface UV products from Ozone Monitoring Instrument observations: An overview, J. Geophys. Res., 112, D24S47, doi:10.1029/2007JD008809, 2007.

Veefkind, J. P., de Leeuw, G., and Durkee, P. A.: Retrieval of aerosol optical depth over land using two angle view satellite radiometry during TARFOX, Geophys. Res. Lett., 25(16), 3135-3138, 1998.

Veihelmann, B., Levelt, P. F., Stammes, P., and Veefkind, J. P.: Simulation study of the aerosol information content in OMI spectral reflectance measurements, Atmos. Chem. Phys., 7, 3115-3127, 2007 , http://www.atmos-chem-phys.net/7/3115/2007/. 